\title{
Spectroscopic characterization of the coordination chemistry and hydrolysis of gallium(III) in the presence of aquatic organic matter
}

\author{
Kristoffer Hagvall $^{1}$, Per Persson ${ }^{1,2}$, Torbjörn Karlsson ${ }^{1, *}$ \\ ${ }^{1}$ Department of Chemistry, Umeå University, SE-901 87 Umeå, Sweden \\ ${ }^{2}$ Centre of Environmental and Climate Research \& Department of Biology, Lund \\ University, SE-223 62, Lund, Sweden \\ * Corresponding author. \\ Tel.: +46907865407. \\ E-mail: torbjorn.karlsson@chem.umu.se (T. Karlsson).
}




\begin{abstract}
Interactions between metals and natural organic matter (NOM) are of great environmental importance and one of the key factors influencing hydrolysis, solubility, and speciation of the metals. However, studying geochemically relevant metals like Al,
\end{abstract} $\mathrm{Fe}$, and $\mathrm{Cu}$ is sometimes associated with analytical problems; for example $\mathrm{Fe}$ and $\mathrm{Cu}$ are both redox active. Gallium $(\mathrm{Ga})$ is a non-redox active metal that usually occurs at very low concentrations in environmental samples and therefore a wide concentration range of Me(III)-NOM species can be explored by adding Ga(III) to such samples. This makes $\mathrm{Ga}(\mathrm{III})$ a good probe and analogue for other metal ions, in particular Al. In addition, due to the increased usage of Ga in society, a better understanding of how Ga interacts with NOM is of importance but such studies are scarce. In this work, Ga(III) interactions with two different organic materials (Suwannee River natural organic matter and Suwannee River fulvic acid) were studied using infrared (IR) and extended X-ray absorption fine structure (EXAFS) spectroscopy in a large experimental range (101-84,076 $\mu \mathrm{g} \mathrm{Ga}^{-1}$ dry weight; $\mathrm{pH}$ 3-8). Our IR spectroscopic results showed that $\mathrm{Ga}(\mathrm{III})$ is bonded mainly to carboxylic functional groups and suggested that only a fraction of the total number of carboxylic sites in the samples was actively involved in the bonding. Modeling of the EXAFS data revealed that $\mathrm{Ga}(\mathrm{III})$ formed mononuclear chelate complexes with NOM that strongly suppressed the hydrolysis and polymerization of $\mathrm{Ga}$ (III). At low $\mathrm{Ga}(\mathrm{III})$ concentrations $\left(1675-16,649 \mu \mathrm{g} \mathrm{g}^{-1}\right)$ organic complexes, consisting of 1 to 3 chelate ring structures, were the dominating species in the entire $\mathrm{pH}$ range while at higher concentrations $\left(67,673-84,076 \mu \mathrm{g} \mathrm{g}^{-1}, \mathrm{pH} 3.0-7.0\right)$ we detected mixtures of mononuclear organic $\mathrm{Ga}(\mathrm{III})$ complexes, $\mathrm{Ga}(\mathrm{III})$ (hydr)oxide, and free $\mathrm{Ga}(\mathrm{III})$ (here defined as the 
hydrated $\mathrm{Ga}(\mathrm{III})$ ion and its soluble hydrolysis products). Moreover, the EXAFS results showed significantly higher contribution from second-shell C atoms (9-11) for the Ga(III)-organic complexes at the lowest concentration (101-125 $\left.\mu \mathrm{g} \mathrm{g}^{-1}, \mathrm{pH} 4.9-5.1\right)$, indicating formation of cage-like structures similar to $\mathrm{Ga}(\mathrm{III})$-EDTA. Our combined results showed that Ga(III)-NOM interactions can be of importance for the solubility and speciation of $\mathrm{Ga}$ in environmental systems. Furthermore, the similarities between $\mathrm{Ga}(\mathrm{III})$ and previous $\mathrm{Fe}(\mathrm{III})$ results demonstrates that $\mathrm{Ga}(\mathrm{III})$ can be utilized as a probe for $\mathrm{Me}(\mathrm{III})-\mathrm{NOM}$ interactions over an extended experimental range (e.g., $\mathrm{pH}$ and metal concentration) and thereby improve our knowledge about these interactions in general.

\section{Introduction}

The fate and behavior of many metals in the environment are strongly influenced by interactions with natural organic matter (NOM). These interactions influence hydrolysis, solubility and thus the speciation of the metals (e.g., Elkins and Nelson, 2002; Xu et al., 2010; Karlsson and Persson, 2012), which in turn affects their mobility, bioavailability and potential toxicity. NOM is formed primarily through degradation of organic material from plants and animals in the environment and consists of a mixture of low molecular weight substances and macromolecules produced by hydrolytic and oxidative decomposition of complex organic compounds such as proteins, carbohydrates, lignins, lipids, and fats (e.g., Ogner and Schnitzer, 1971; Rouhi, 2000). It is abundant in most natural systems such as soils and surface waters and contributes greatly to the accessible terrestrial and aquatic carbon in the environment. Generally, NOM has a high capacity to complex metal ions via the coordination to a variety of functional groups (e.g., carboxyls, 
phenols, amine, thiols) present in this material (Essington, 2004). Gallium (Ga) is known to form stable complexes with organic functional groups (Clausén et al., 2003; Clausén et al., 2005) and interactions with NOM will probably have a significant influence on the speciation of Ga in environmental systems. Due to the toxicity of Ga (Lin and Hwang, 1998; Yang and Chen, 2003) the increased usage in society, e.g., in the electronic industry (Yu and Liao, 2011) and cancer treatment (Collery et al., 2002), could potentially cause environmental problems and therefore it is important to increase our understanding of how Ga interacts with NOM, but studies of these interactions are scarce.

In order to get detailed molecular-level information about the interactions between metals and organic matter in environmental systems, different spectroscopic techniques can be applied. Synchrotron-based extended X-ray absorption fine structure (EXAFS) spectroscopy and X-ray absorption near edge structure (XANES) spectroscopy as well as infrared (IR) spectroscopy have been shown to provide useful molecular-scale information on metal-NOM interactions (e.g., Elkins and Nelson, 2002; Duckworth et al., 2009; Xu et al., 2010; Karlsson and Persson, 2012). These techniques are complementary and make it possible to probe both the metal (EXAFS/XANES) and the functional groups (IR) involved in the interactions. However, in some cases, the properties of the studied systems limit the applicability of the techniques. For example, the low K-edge energy $(1.5596 \mathrm{keV})$ of aluminum ( $\mathrm{Al})$ results in strong background absorption and, as a consequence, only highly concentrated samples can be analyzed. In the case of the redoxactive metal iron $(\mathrm{Fe})$, the intense $\mathrm{X}$-ray beam can induce redox transformations during the measurements. Furthermore $\mathrm{Al}$ and $\mathrm{Fe}$ occur at relatively high concentrations in natural samples making it difficult to determine the coordination of complexes formed at 
low concentrations without somehow pre-washing NOM with the risk of further altering the material. In this respect, $\mathrm{Ga}(\mathrm{III})$ can be used as a suitable probe and analogue for metal ions with high charge-to-radius ratios. Gallium has a high K-edge energy (10.367 $\mathrm{keV}$ ) making it readily accessible with EXAFS; it is not redox active and usually occurs at very low concentrations in environmental samples. Furthermore, since the hydrolysis and coordination chemistry of $\mathrm{Fe}(\mathrm{III}), \mathrm{Al}(\mathrm{III})$ and $\mathrm{Ga}(\mathrm{III})$ are very similar (Baes and Mesmer, 1976; Bénézeth et al., 1997; Clausén et al., 2003; Clausén et al., 2005; Persson and Axe, 2005), studies of $\mathrm{Ga}(\mathrm{III})-\mathrm{NOM}$ systems may be used to increase our understanding of $\mathrm{Fe}(\mathrm{III}) / \mathrm{Al}(\mathrm{III})-\mathrm{NOM}$ interactions. To our knowledge, there are no previous EXAFS or XANES studies on $\mathrm{Al}(\mathrm{III})$ - or Ga(III)-NOM interactions but some infrared spectroscopic results from $\mathrm{Al}(\mathrm{III})$-fulvic acid systems have been published (e.g., Patterson et al., 1992; Elkins and Nelson, 2002). In these studies, salicylic- and phthalicacid-like sites were suggested as likely coordination sites for $\mathrm{Al}(\mathrm{III})$. Interactions between Fe(III) and NOM have been studied using both EXAFS and IR spectroscopy and the results showed that the interactions are mainly due to carboxylic functional groups in the pH range 3-7 (Karlsson and Persson, 2010; Sharma et al., 2010; Karlsson and Persson, 2012). However, these studies were performed at rather high metal concentrations ( $>90$ $\mu \mathrm{mol} \mathrm{Fe} \mathrm{g}^{-1}$ organic matter) and problems with beam-induced reduction during EXAFS measurements were reported at low Fe concentrations (Karlsson and Persson, 2012).

In this work we have used infrared and EXAFS spectroscopy to study Ga(III) interactions with aquatic NOM, from the Suwannee River, at varying metal concentrations and $\mathrm{pH}$ values. The main aims were to determine the structure of the $\mathrm{Ga}(\mathrm{III})-\mathrm{NOM}$ complexes formed, follow the hydrolysis and polymerization of $\mathrm{Ga}(\mathrm{III})$ in 
this system, and evaluate if $\mathrm{Ga}(\mathrm{III})$ can be used as a probe to extend our knowledge about metal-NOM interactions in general. Knowledge about these interactions is needed to better understand the behavior metals in soils and waters.

\section{Material and methods}

\subsection{Samples and sample preparation}

Suwannee River Natural Organic Matter (SRN; 1R101N) and Suwannee River Fulvic Acid (SRFA; 1S101F) were purchased from the International Humic Substances Society (IHSS). Selected chemical data for these materials are presented in Table S1, Supplementary data. The Suwannee River is classified as a blackwater river that receives water from the Okefenokee Swamp. The area consists of extensive peat deposits but the majority of the dissolved organic carbon (DOC) in the Suwannee River is believed to come from decomposing vegetation. The DOC content of the river ranges from 25 to 75 $\mathrm{mg} \mathrm{L}^{-1}$, which lowers the $\mathrm{pH}$ to less than 4.0 (Averett et al., 1994). The SRN material was collected through reverse osmosis (Serkiz and Perdue, 1990), and the isolated freezedried organic matter contained hydrophobic and hydrophilic acids and other soluble organic molecules present in the river water, with no fractionation dependent on size or structure of the molecules present. To isolate the SRFA material, the XAD-8 resin adsorption method was used. This method fractionates the DOC into hydrophobic and hydrophilic fractions through preferential adsorption of the hydrophobic fraction on the XAD-8 resin. The hydrophobic fraction is then eluted from the resin by the addition of aqueous $\mathrm{NaOH}$. Small organic acids (MW<200 Da) are eluted in one fraction and what is considered aquatic humus in another fraction, resulting in a size fractionation of the 
material. The humic acid is then removed from the aquatic humus fraction by precipitation at low $\mathrm{pH}$. Finally, a desalting step involving cation exchange is used to obtain the fulvic acid. Thus, the freeze-dried fulvic acid used (SRFA) contained only hydrophobic organic acids with molecular weights larger than 200 Da (Thurman and Malcolm, 1981).

\subsubsection{Infrared spectroscopy}

Samples for infrared analysis were prepared by adding $28 \mathrm{mg}$ of the SRN and $27 \mathrm{mg}$ of the SRFA material (dry weight) into $1.5 \mathrm{~mL}$ Eppendorf tubes followed by addition of $\mathrm{GaCl}_{3}$ (anhydrous beads 99.99\%, Sigma-Aldrich) dissolved in Milli-Q water ( $\mathrm{pH} 1.1$ ). The suspensions with $\mathrm{Ga}$ and organic matter were allowed to equilibrate for 10 minutes before $\mathrm{pH}$ was adjusted to 3.1-7.9 with $\mathrm{NaOH}(2 \mathrm{M})$, and the ionic strength to $0.270 \mathrm{M}$ by addition of $\mathrm{NaCl}(0.6 \mathrm{M})$. This resulted in $\mathrm{Ga}(\mathrm{III})$ concentrations of $23,451-67,673 \mu \mathrm{g}$ $\mathrm{g}^{-1}$ and $84,076 \mu \mathrm{g} \mathrm{g}^{-1}$ for SRN and SRFA, respectively. All concentrations were on a dry mass basis and corresponded to a molar ratio of $0.070-0.202 \mathrm{~mol} \mathrm{Ga(III)}$ per mol of carboxylic functional groups (R-COOH) for SRN and 0.202 mol Ga(III) per mol R$\mathrm{COOH}$ for SRFA. The total volume of each sample was adjusted to $0.5 \mathrm{~mL}$ by addition of Milli-Q water followed by equilibration on a rotating mixer for $24-72 \mathrm{~h}$. The samples were stored in a refrigerator at $8^{\circ} \mathrm{C}$ until the infrared analysis, and the $\mathrm{pH}$ was measured using a pH combination electrode (InLab®Micro, Mettler Toledo) and a pH meter (SevenMulti modular meter system, Mettler Toledo) prior to the infrared analysis. Reference samples were prepared in the same way but without addition of $\mathrm{GaCl}_{3}$ in the $\mathrm{pH}$ range 3.1-8.1 for SRN and 3.0-6.9 for SRFA and with a total volume of $0.3 \mathrm{~mL}$. For 
the deuterium samples (IR_SRN_16-21; Table S2, Supplementary data), the SRN material was washed with $\mathrm{D}_{2} \mathrm{O}(99.5 \%$, purchased from Cambridge Isotope Labs) once and then freeze-dried. The $\mathrm{NaCl}$, as well as the $\mathrm{GaCl}_{3}$, was dried and dissolved in $\mathrm{D}_{2} \mathrm{O}$ before use. $\mathrm{NaOD}$ was purchased from Cambridge Isotope Labs $\left(99.5 \%, 40 \%\right.$ in $\left.\mathrm{D}_{2} \mathrm{O}\right)$ and added to the samples to get the desired $\mathrm{pD}$ values. $\mathrm{pH}$ was measured using a $\mathrm{pH}$ combination electrode (as above) and a correction factor of +0.44 was used to calculate pD (Mikkelsen and Nielsen, 1960). Data for the IR SRN samples, for which spectra are shown in 3.1, are presented in Table 1 and data for the remaining IR samples are presented in Table S2, Supplementary data.

\section{Table 1}

\subsubsection{EXAFS spectroscopy}

The EXAFS samples were prepared by adding 18-46 mg of SRN or SRFA, based on dry weight, to $1.5 \mathrm{~mL}$ Eppendorf tubes. $\mathrm{GaCl}_{3}$ dissolved in Milli-Q water ( $\left.\mathrm{pH} 1.1\right)$ were added to the samples resulting in $\mathrm{Ga}(\mathrm{III})$ concentrations in the range $101-67,673 \mu \mathrm{g} \mathrm{g}^{-1}$ for the SRN samples and $125-84,076 \mu \mathrm{g} \mathrm{g}^{-1}$ for SRFA. All concentrations were on a dry mass basis and correspond to molar ratios of 0.0003 to $0.202 \mathrm{~mol} \mathrm{Ga(III)} \mathrm{per} \mathrm{mol} \mathrm{R-}$ $\mathrm{COOH}$. The suspensions with $\mathrm{Ga}$ and organic matter were equilibrated for 10 minutes and then $\mathrm{pH}$ was adjusted to between 3.0 and 6.9 for SRN and to between 2.9 and 7.0 for SRFA by addition of $\mathrm{NaOH}$ ( $2 \mathrm{M}$ ). The ionic strength was adjusted to $0.270 \mathrm{M}$ by addition of $\mathrm{NaCl}(0.6 \mathrm{M})$ and the total volume to 0.25 or $0.5 \mathrm{~mL}$ by addition of Milli-Q water. Subsequently, the samples were equilibrated on a rotating mixer for $24-72 \mathrm{~h}$. 
Finally, $\mathrm{pH}$ was measured using a $\mathrm{pH}$ combination electrode (as above), and the samples were stored for 5-12 days in a refrigerator at $8^{\circ} \mathrm{C}$ prior to EXAFS analysis. At the beamline, the samples were transferred to a Teflon holder and sealed with Kapton tape (CHR-Furon). Characteristics of the EXAFS samples are presented in Table 2.

\section{Table 2}

An aqueous paste of amorphous $\mathrm{Ga}(\mathrm{OH})_{3(\mathrm{~s})}$ (Persson et al., 2006) and aqueous solutions of $\mathrm{Ga}$ (III)-EDTA $\left[\mathrm{Ga}\left(\mathrm{C}_{10} \mathrm{H}_{12} \mathrm{~N}_{2} \mathrm{O}_{8}\right)^{-}\right]$(Norén and Persson, 2010), $\mathrm{Ga}$ (III)Oxalate $\left[\mathrm{Ga}\left(\mathrm{C}_{2} \mathrm{O}_{4}\right)_{3}{ }^{3-}\right]$ (Clausén et al., 2003), $\mathrm{Ga}(\mathrm{III})$-Citrate $\left[\mathrm{Ga}\left(\mathrm{C}_{6} \mathrm{H}_{5} \mathrm{O}_{7}\right)_{2}{ }^{3-}\right]$ (Clausén et al., 2005) and $\mathrm{Ga}(\mathrm{III})$-Nitrate $\left[\mathrm{Ga}\left(\mathrm{NO}_{3}\right)_{3}\right]$ (Clausén et al., 2002) were selected as EXAFS reference samples for comparison with the Ga(III)-NOM samples.

\subsection{Data collection and treatment}

\subsubsection{Infrared spectroscopy}

The infrared spectra were collected using a Bruker Vertex 80v FTIR spectrometer equipped with a RT-DLaTGS (deuterated triglycine sulfate) detector and a singlereflection, $45^{\circ}$, ZnSe ATR crystal (FastIR, Harrick Scientific). Each sample was scanned 512 times in the range $520-7500 \mathrm{~cm}^{-1}$ at a resolution of $4 \mathrm{~cm}^{-1}$. The samples were added directly onto the ZnSe crystal and analyzed at room temperature. During data collection the sample compartment was kept under vacuum, but a vacuum-tight lid protected the sample. To extract the spectra of the NOM (SRN and SRFA) samples, the absorption of the empty cell was collected as the background and a spectrum of the ionic medium was 
collected in order to remove this contribution from the sample spectra. The resulting spectra show the IR spectral features of the organic matter with and without addition of $\mathrm{Ga}(\mathrm{III})$. To isolate the IR spectral characteristics of the Ga(III)-NOM complexes, difference spectra were calculated by subtracting the spectra of protonated and nonprotonated NOM from NOM spectra with added Ga(III). The isolation of the nonprotonated NOM was done by subtracting a spectra where the NOM was fully protonated (e.g., IR_SRN1; pH 3.1) from a spectra of the fully non-protonated NOM (e.g., IR_SRN6; pH 8.1) focusing on the protonated carboxylic stretching mode at ca. $1700 \mathrm{~cm}^{-}$

1. The isolation of the protonated NOM was done in the same way focusing on the symmetric carboxylic stretching mode at ca. $1400 \mathrm{~cm}^{-1}$. The data treatment (as well as controlling the spectrometer) was accomplished by the OPUS software (Bruker).

\subsubsection{EXAFS spectroscopy}

The Ga K-edge (10.367 keV) EXAFS spectra were collected at the multi-pole wiggler beamline 4-1 at Stanford Synchrotron Radiation Lightsource (SSRL), Stanford University, USA. SSRL was operated at $3.0 \mathrm{GeV}$ ring energy and at currents around 350 $\mathrm{mA}$ in top-up mode. The detector system included three consecutive ion chambers that were filled with $\mathrm{N}_{2}$ to monitor the transmitted beam and an Ar-filled Lytle detector for

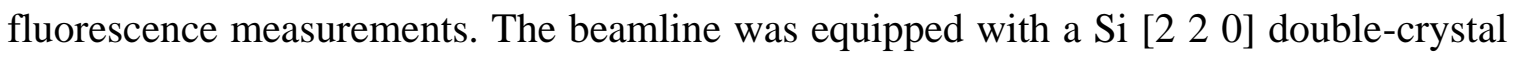
monochromator, and to eliminate higher order harmonics it was detuned by $30 \%$. The spectra of the SRN and SRFA samples were collected at room temperature in fluorescence mode using the Lytle detector. Samples were positioned at a $45^{\circ}$ angle to the beam and, to reduce unwanted fluorescence and scattering contributions to the signal, a 
Zn 3- $\mu x$ filter and Soller slits were used. The spectra $\left(I_{\mathrm{f}} / I_{0}\right.$ versus energy) were collected in the energy range from $227 \mathrm{eV}$ before the edge to $880 \mathrm{eV}$ after the edge in a step-scan mode. The scan step-sizes were $10 \mathrm{eV}$ before the edge, $0.35 \mathrm{eV}$ over the edge, and 0.05 $\AA^{-1}$ in the EXAFS region. Internal calibration was performed by simultaneously

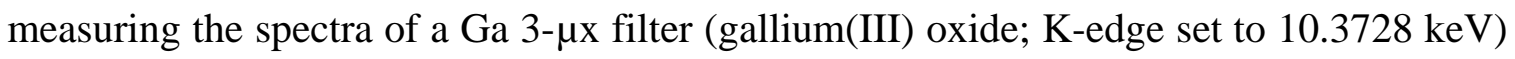
in transmission mode throughout the duration of all scans. The spectrum for each sample represents the average of 1-39 scans. Spectra of SRN1-7 and SRFA1-3 and 5 are from one scan only; for the rest of the samples all individual scans were checked for possible beam damage, but no beam-induced changes were detected.

The EXAFS data treatment was performed using SIXPack v1.01 (Webb, 2005). To normalize the data over the edge, a linear pre-edge function and a second-order polynomial post-edge function was subtracted from each averaged spectrum. Above the absorption edge a cubic spline was used to remove the background. The normalized and background subtracted spectra were $k^{3}$-weighted to enhance the higher $k$-values and Fourier transformed over the $k$-interval from ca. 3.0 to $10.3-15.0 \AA^{-1}$ (depending on data quality), using a Kaiser-Bessel window function. The spectra were quantitatively evaluated in $R$-space using a non-linear least-squares refinement procedure with theoretical phase and amplitude functions calculated by the ab initio code FEFF7 (Zabinsky et al., 1995). $\mathrm{Ga}\left(\mathrm{C}_{2} \mathrm{O}_{4}\right)_{3}{ }^{3-}$ and $\mathrm{GaO}(\mathrm{OH})$ (Clausén et al., 2003; $\mathrm{Li}$ et al., 2003) were used as input structures in the FEFF calculations. The EXAFS amplitudes are proportional to the coordination number $(\mathrm{CN})$ and the amplitude reduction factor, $\mathrm{S}_{0}^{2}$, hence reference samples with known structures were used to determine $\mathrm{S}_{0}{ }^{2}$. For all the SRN and SRFA samples the EXAFS spectrum of an acidic $\mathrm{Ga}\left(\mathrm{NO}_{3}\right)_{3}$ solution, where the 
$\mathrm{CN}$ for $\mathrm{Ga}-\mathrm{O}$ in $\mathrm{Ga}\left(\mathrm{H}_{2} \mathrm{O}\right)_{6}{ }^{3+}$ is known to be 6 (Lindqvist-Reis et al., 1998), was used. By fitting this spectrum with a fixed $\mathrm{CN}$ of 6.0 in the first coordination shell, a $\mathrm{S}_{0}{ }^{2}$ value of $1.21 \pm 0.09$ was obtained. The threshold energy $\left(\Delta \mathrm{E}_{\mathrm{o}}\right)$ was varied but correlated to be the same for all shells. Whenever possible, the quantitative EXAFS modeling was further constrained by correlating CNs and fixing Debye-Waller factors $\left(\sigma^{2}\right)$. The scattering paths used to model organic Ga structures were those from a mononuclear $\mathrm{Ga}\left(\mathrm{C}_{2} \mathrm{O}_{4}\right)_{3}{ }^{3-}$ complex (Fig. 1), a choice motivated by the IR spectroscopic results (see below) indicating Ga(III) coordination to carboxylate groups of the SRN and SRFA materials. The Debye-Waller factors of the Ga-C, Ga-O-C, and Ga-C-O scattering paths (Fig. 1) were determined via fits of SRN and SRFA spectra (SRN9 and SRFA7; Table 2) that showed no indications of Ga-Ga contributions in higher coordination shells and were prepared at $\mathrm{pH} 4.9$ and 4.7, respectively, where contribution from free $\mathrm{Ga}(\mathrm{III})$ (here defined as the hydrated Ga(III) ion and its soluble hydrolysis products) was considered to be small. These Debye-Waller factors were used as fixed parameters during the refinement of the remaining SRN and SRFA samples (Table 3). The Debye-Waller factors of the Ga-Ga scattering paths were obtained by fitting the $\mathrm{Ga}(\mathrm{OH})_{3(\mathrm{~s})}$ spectrum with fixed $\mathrm{CN}$ :s for the Ga-Ga paths, according to data presented by Pokrovski et al. (2002) for $\alpha-\mathrm{GaOOH}$, and used as fixed parameters for the SRN and SRFA samples. The idea behind these relatively constrained fits was to facilitate the comparison between samples and to reveal trends in the data depending on $\mathrm{pH}$ and $\mathrm{Ga}(\mathrm{III})$ concentration. As a result of these constraints, the number of free variables in the fitting procedure (4-11) never exceeded the number of independent points (12-20) as calculated by the Nyquist theorem $\left(\mathrm{N}_{\text {ind }}=(2 \times \Delta k \times \Delta R) /\right.$ $\pi$, where $\Delta k$ is the $k$-range of the EXAFS spectrum and $\Delta R$ is the R-range of the FT 
considered) and the degree of freedom was never below 4. Further details of the fitting procedure are found in Table 3.

In addition to the quantitative fitting procedure described above, a qualitative interpretation of the nature of backscattering of atoms in higher coordination shells was carried out using the wavelet transform (WT) method as implemented in the Igor Pro script developed by Funke et al. (2005). The WT results are typically visualized as a contour plots in three dimensions: the wave vector $(k)$, the interatomic distance uncorrected for phase shifts (R), and the WT modulus. The different backscattering atoms appear as ridges with high intensity and since heavy elements show contributions at higher $k$-values compared to lighter elements the locations of these ridges help to differentiate between light and heavy backscattering atoms. All EXAFS spectra were analyzed using the Morlet-wavelet function and different values of $\eta$ and $\sigma$ were used depending on the resolution of the wavelet plot. Since the resolution of the plots critically depends on the selection of these Morlet parameters (Funke et al., 2005), different values were tested in order to optimize the resolution in both $k$ and $R$ space for our samples.

Fig. 1.

\section{Results and discussion}

\subsection{Infrared spectroscopy}

IR spectroscopic data collected for both the Ga(III)-SRN and Ga(III)-SRFA systems showed that they behaved in a very similar fashion. Hence, the discussion will be focused on the Ga(III)-SRN results, and the fulvic acid results will primarily be presented as 
Supplementary data (Fig. S1). Fig. 2 shows IR spectra of SRN collected in the absence and presence of $\mathrm{Ga}(\mathrm{III})$ as a function of $\mathrm{pH}$, and the region displayed is dominated by bands originating from carbohydrates as well as carboxylic functional groups, as discussed in previous works (Persson and Axe, 2005; Karlsson and Persson, 2012). Furthermore, protonation/deprotonation reactions of these carboxylic groups are the primary cause of the pH-dependent IR spectroscopic features of SRN (Karlsson and Persson, 2012). These $\mathrm{pH}$-induced spectroscopic changes were manifested as an increase of the symmetric and asymmetric carboxylate stretching frequencies at ca. 1400 and 1600 $\mathrm{cm}^{-1}$, respectively, with increasing $\mathrm{pH}$ whereas the carbonyl and the $\mathrm{C}-\mathrm{O}-\mathrm{H}$ modes of the carboxylic acid decreased concomitantly (Fig. 2). In the presence of Ga(III), two key observations were the loss of carbonyl intensity relative to the asymmetric carboxyl band at low $\mathrm{pH}$ as well as a shift of the latter to a higher frequency (Fig. 2). These observations suggested that $\mathrm{Ga}(\mathrm{III})$ outcompeted some of the carboxylic protons and thus become coordinated directly to carboxylate groups. We detected no major involvement from other functional groups such as hydroxyls under the current experimental conditions; note that there are 2.5 and 3.9 times more carboxyl groups than phenols in SRN and SRFA, respectively (Table S1, Supplementary data). However, we cannot rule out coordination via other functional groups, especially at lower concentrations, as the detection limits of IR spectroscopy may prevent observation of these interactions.

\section{Fig. 2.}


In order to isolate the IR spectral characteristics of the Ga(III)-SRN complexes, difference spectra were calculated by subtracting the spectra of protonated and nonprotonated SRN from the spectra of $\mathrm{Ga}(\mathrm{III})-\mathrm{SRN}$ as explained in the experimental section (Fig. 3). The difference spectra displayed symmetric and asymmetric carboxylate stretching frequencies at 1432 and $1615 \mathrm{~cm}^{-1}$, respectively, and these were substantially different from the two groups of SRN carboxylate frequencies previously identified in the absence of metal ions at 1394 and $1566 \mathrm{~cm}^{-1}$ and 1390 and $1590 \mathrm{~cm}^{-1}$ (Karlsson and Persson, 2012). The shift of the asymmetric stretching vibration to higher wavenumbers in the presence of $\mathrm{Ga}(\mathrm{III})$ was in accordance with previous studies on $\mathrm{Ga}(\mathrm{III})$-carboxylate complexes and indicated inner-sphere coordination between $\mathrm{Ga}(\mathrm{III})$ and the carboxylate groups of SRN (Clausén et al., 2003; Clausén et al., 2005). As the strong bending mode of water at ca. $1640 \mathrm{~cm}^{-1}$ may cause problems in properly isolating the asymmetric carboxylate stretching band, we also conducted an experiment in $\mathrm{D}_{2} \mathrm{O}$. In this solvent there is no overlap between these bands and the results obtained corroborated the existence of a $\mathrm{Ga}(\mathrm{III})$-carboxylate interaction in SRN characterized by an asymmetric carboxylate stretching vibration around $1610-1620 \mathrm{~cm}^{-1}$ (Fig. S2, Supplementary data). Furthermore, the difference spectra showed that the concentration of SRN Ga(III)carboxylate complexes decreased with increasing $\mathrm{pH}$, and that these changes were concomitant with an increase in the carbohydrate bands (Figs. 2 and 3). These trends were in accordance with previous Fe(III)-SRN results that showed that mononuclear Fe(III)-carboxylate complexes were consumed and converted into ferrihydrite by raising the $\mathrm{pH}$ (Karlsson and Persson, 2012). The increase of the carbohydrate bands indicated that such molecules could play a role in the formation and stabilization of the presumably 
small ferrihydrite particles. By analogy, the results presented in Figs. 2 and 3 suggest that an increase in $\mathrm{pH}$ causes a conversion of mononuclear $\mathrm{Ga}$ (III)-SRN complexes into $\mathrm{Ga}(\mathrm{OH})_{3(\mathrm{~s})}$, where the latter species is somehow interacting with carbohydrates. Similar observations were made for the Ga(III)-SRFA system (Fig. S1, Supplementary data), although in this case the $\mathrm{pH}$-dependent changes of the carbohydrate bands were not as pronounced.

\section{Fig. 3.}

If we assume that the carboxylate peak areas of the difference spectra (Fig. 3) are representative of the amount of $\mathrm{Ga}(\mathrm{III})-\mathrm{SRN}$ complexes, then these can be used to estimate the fraction of carboxylate groups involved in the interaction with $\mathrm{Ga}(\mathrm{III})$ by calculating the ratios between these areas and the total area of the carboxyl bands (Fig. 4). The calculated ratios showed that $\mathrm{Ga}(\mathrm{III})-\mathrm{SRN}$ complexes were favored at low $\mathrm{pH}$, as already discussed, and at a total $\mathrm{Ga}(\mathrm{III})$ to $\mathrm{R}-\mathrm{COOH}$ molar ratio of 0.202 , a maximum of ca. $20 \%$ of the carboxylate groups were indeed coordinated to Ga(III) (Fig. 4). Accordingly, the 1:1 ratio between $\mathrm{Ga}(\mathrm{III})$ and coordinated carboxylate groups together with previous observations that metal ions coordinate to NOM as chelate structures involving several functional groups (Manceau and Matynia, 2010; Karlsson and Persson, 2012) implies that at the $0.202 \mathrm{Ga}(\mathrm{III})$ to $\mathrm{R}-\mathrm{COOH}$ molar ratio, a substantial fraction of $\mathrm{Ga}(\mathrm{III})$ must not be coordinated to carboxyl groups, as will be discussed in the EXAFS section. Interestingly, the results indicated that fulvic acid has an even smaller fraction of carboxyl groups available for Ga(III) coordination (Fig. 4). This difference could be due 
to the methods used to isolate the two materials (Thurman and Malcolm, 1981; Serkiz and Perdue, 1990). In the SRFA material, small organic acids ( $<200 \mathrm{Da})$ are removed during isolation while they are included in the SRN material. Thus, the small organic acids present in the SRN material could make more carboxylic sites available for binding.

\section{Fig. 4.}

\subsection{EXAFS spectroscopy}

\subsubsection{Wavelet transform analysis}

The results from the WT analysis for the SRN and SRFA samples showed similar first-shell contributions with a backscattering maximum around $6 \AA^{-1}$, in accordance with the Ga-O scattering of the $\mathrm{Ga}\left(\mathrm{C}_{2} \mathrm{O}_{4}\right)_{3}{ }^{3-}$ reference sample (Fig. S3, Supplementary data). The WT results of the higher coordination shells in SRN and SRFA displayed similar features (Fig. 5 and Fig. S4, Supplementary data). At the highest Ga(III) concentration (0.202 mol Ga/mol R-COOH) and $\mathrm{pH}$ values of 4.8-7.0, the high-resolution WT showed a distinct feature at ca. $7-8 \AA^{-1}$ and $2.7 \AA$ corresponding to the second peak in the Fourier transform (FT) (Fig. 5c and d; Fig. S4h, Supplementary data). This feature was also present in the $\mathrm{Ga}(\mathrm{OH})_{3(\mathrm{~s})}$ reference sample (Fig. 5a) and originates from $\mathrm{Ga}-\mathrm{Ga}$ backscattering. At the same $\mathrm{Ga}(\mathrm{III})$ concentration but lower $\mathrm{pH}$ values (3.0-4.2), no signals were detected from Ga in the second shell probably due to a substantial amount of free $\mathrm{Ga}(\mathrm{III})$ in these samples (Fig. 5b and Fig. S4f, Supplementary data).

At lower concentrations $(0.0003-0.04 \mathrm{~mol} \mathrm{Ga} / \mathrm{mol} \mathrm{R}-\mathrm{COOH})$, no contribution from Ga was detected in the investigated $\mathrm{pH}$ range (2.9-6.9). Instead, these samples displayed 
strong FT features at distances of about 2.0-2.5 $\AA$ and 3.0-3.8 $\AA$ that appeared at lower energies $\left(2-6 \AA^{-1}\right)$ in the WT plots, which indicated backscattering from lighter atoms (Fig. 5f, $\mathbf{g}$ and $\mathbf{h}$ and Fig. S4j, $\mathbf{l}$ and $\mathbf{n}$, Supplementary data). These features were in fair agreement with those of single and multiple backscattering from $\mathrm{C} / \mathrm{O}$ in the second and third coordination shells of $\mathrm{Ga}\left(\mathrm{C}_{2} \mathrm{O}_{4}\right)_{3}{ }^{3-}, \mathrm{Ga}\left(\mathrm{C}_{6} \mathrm{H}_{5} \mathrm{O}_{7}\right)_{2}{ }^{3-}$, and $\mathrm{Ga}\left(\mathrm{C}_{10} \mathrm{H}_{12} \mathrm{~N}_{2} \mathrm{O}_{8}\right)^{-}$(Fig. $5 \mathbf{e}$ and Fig. S4c and d, Supplementary data), suggesting that mononuclear organic Ga(III) complexes were the predominating species in the SRN and SRFA samples under these conditions. These observations divided the samples into two main categories depending on $\mathrm{Ga}(\mathrm{III})$ concentration and $\mathrm{pH}$, one with only light atoms in higher coordination shells and the other with a mixture of light and $\mathrm{Ga}(\mathrm{III})$ atoms.

\section{Fig. 5.}

\subsubsection{Quantitative EXAFS analysis}

The quantitative EXAFS fits showed that Ga(III) in both the SRN and SRFA systems was coordinated to O/N atoms at a first-shell distance of about $1.96 \AA$. This was in agreement with 6-coordinated complexes, presumably in an approximate octahedral configuration (Lindqvist-Reis et al., 1998; Table 3 and Table S4, Supplementary data). In the samples with the highest $\mathrm{Ga}(\mathrm{III})$ concentrations $(0.202 \mathrm{~mol} \mathrm{Ga} / \mathrm{mol} \mathrm{R}-\mathrm{COOH})$, a slight decrease in the distance of the Ga-O scattering path with increasing $\mathrm{pH}$ was observed, from $1.96 \AA$ at pH 3.0-3.1 to 1.93-1.94 $\AA$ at pH 6.8-7.0 (Table 3, SRN1-5 and SRFA1-3). This could indicate a partial shift from a 6-coordinated structure to a 4-coordinated $\mathrm{Ga}(\mathrm{OH})_{4}{ }^{-}$ structure, which is supported by the distribution diagram (Fig. 6). However, the XANES 
spectra show similar edge positions in the whole $\mathrm{pH}$ range for these samples indicating that 6-coordination dominates (Figs. S5 and S6, Supplementary data).

\section{Table 3}

In accordance with the WT results, the samples with a $\mathrm{Ga}$ (III) to $\mathrm{R}-\mathrm{COOH}$ ratio of 0.04 and below (21.5-0.27 mM Ga, $\mathrm{pH} 2.9-6.9$; Table 2) were successfully modeled using 2nd and 3rd shell scattering paths from organic structures only (Table 3 and Figs. 1 and 7 and Fig. S7, Supplementary data). This should be compared to the distribution diagrams of $\mathrm{Ga}(\mathrm{III})$, which are dominated by amorphous $\mathrm{Ga}(\mathrm{OH})_{3(\mathrm{~s})}$ from $\mathrm{pH} 3-3.5$ to about 6-8.5, depending on total Ga(III) concentration (Fig. 6). Thus, the addition of organic matter suppresses the hydrolysis and polymerization of $\mathrm{Ga}(\mathrm{III})$ and this effect has been demonstrated for other metals ions, e.g., Fe(III) (Mikutta, 2011; Karlsson and Persson, 2012). Very recently the high stability of metal-NOM complexes has also been revealed by $\mathrm{Fe}$ isotope studies of organic-rich waters (Ilina et al., 2013). The obtained Ga-C, Ga-O-C, and Ga-C-O distances were in fair accordance with distances in $\mathrm{Ga}\left(\mathrm{C}_{2} \mathrm{O}_{4}\right)_{3}{ }^{3-}$ (Table 3 and Table S4, Supplementary data), indicating a chelate structure as described by Clausén et al. $(2003,2005)$ for oxalate, malonate, and citrate. Recent studies have shown that $\mathrm{Fe}$ and $\mathrm{Cu}$ can form 5- or 6-membered chelate ring structures in similar NOM systems (Karlsson et al., 2006; Karlsson and Persson, 2010; Manceau and Matynia, 2010; Karlsson and Persson, 2012). The observed ability of NOM to suppress the hydrolysis and polymerization of $\mathrm{Ga}(\mathrm{III})$ is also in accordance with formation of chelate ring structures. A comparsion between stability constants $\left(\log \mathrm{K}_{1}\right.$; $\left.[\mathrm{ML}] /[\mathrm{M}][\mathrm{L}]\right)$ for 
$\mathrm{Ga}(\mathrm{III})$ complexes with $\mathrm{O}$ - and $\mathrm{N}$-functional groups typical of natural organic matter, e.g., carboxylic acids (oxalic 7.06 (I=1.0 M; Perrin, 1979) and salicylic 14.5 ( $\mathrm{I}=0.1 \mathrm{M}$; Martell and Smith, 1982)), phenols (catechol 18.9 (I=0.1 M; Perrin, 1979), and amines (glycine 9.33 (I=0.1 M; Perrin, 1979)), shows that $\mathrm{Ga}(\mathrm{III})$ also has a high affinity for catechol-like sites. Furthermore, the affinity for artificial chelating agents like EDTA is even higher than for catechol $\left(\log \mathrm{K}_{1} 21.0(\mathrm{I}=0.1 \mathrm{M})\right.$; Martell and Smith, 1982). Thus, especially at the lower concentrations involvement from other functional groups than carboxyls is a possibility and cannot be ruled out, but this cannot be ascertained by our spectroscopic data. Phosphoryl groups could theoretically also be of importance as shown for other metals (e.g., Cd; Boyanov et al., 2003). However, the phosphor content in SRN and SRFA is too low for these groups to have any influence on the average coordination of $\mathrm{Ga}$ at the studied concentrations (Table S1, Supplementary data). The obtained Ga-C, Ga-O-C, and Ga-C-O distances in our samples could be averages of several distances originating from different functional groups, but it should be noted that the concentration of carboxylic groups in SRN and SRFA are substantially higher than the concentrations of these other groups (Table S1, Supplementary data).

\section{Fig. 6.}

\section{Fig. 7.}

At a molar ratio of $0.04 \mathrm{~mol} \mathrm{Ga} / \mathrm{mol} \mathrm{R}-\mathrm{COOH}$, a decrease in the $\mathrm{CN}$ for $\mathrm{C}$ is observed for both SRN and SRFA with decreasing pH (Table 3, SRN6-8 and SRFA4-6). 
This indicated a contribution from free $\mathrm{Ga}$ (III) in the samples with the lowest $\mathrm{pH}(\mathrm{pH}$ 2.9-3.3) and that a greater proportion of the $\mathrm{Ga}(\mathrm{III})$ is bonded to NOM at higher $\mathrm{pH}$. Although the $\mathrm{CN}$ for $\mathrm{Ga}-\mathrm{C}$ at $\mathrm{pH} 5.0$ to 6.9 is between 3.0 and $3.8, \mathrm{Ga}(\mathrm{III})$ is most probably completely complexed by NOM since these samples are supersaturated with respect to precipitation of $\mathrm{Ga}(\mathrm{OH})_{3(\mathrm{~s})}$ (Fig. 6). At lower molar ratio $(0.005 \mathrm{~mol} \mathrm{Ga} / \mathrm{mol} \mathrm{R}$ $\mathrm{COOH}$ ) and a pH around 5, the $\mathrm{CN}$ of the Ga-C scattering path is around 6-7 (Table 3), in accordance with $\mathrm{Ga}\left(\mathrm{C}_{2} \mathrm{O}_{4}\right)_{3}{ }^{3-}$, which has a structure with three 5-membered chelate rings (Fig. 1 and Table S4, Supplementary data). A visual comparison between the spectra in Fig. 7 (spectra $\mathbf{c}$ and $\mathbf{e}$ ) also indicated a change towards a structure similar to $\mathrm{Ga}\left(\mathrm{C}_{2} \mathrm{O}_{4}\right)_{3}{ }^{3-}$ with decreasing molar ratio.

The lowest Ga(III) concentrations (0.0003-0.0012 mol Ga/mol R-COOH; pH 4.9-5.2) showed the most pronounced second and third coordination shell contributions and also a more distinct split at the top of the second oscillation in $k$-space (Fig. $5 \mathbf{h}$; Fig. 7 spectra $\mathbf{f}$ and $\mathbf{g}$ and Fig. S4n, w, and $\mathbf{x}$ and Fig. S7 spectra e and $\mathbf{f}$, Supplementary data). This was accompanied by an increase in the $\mathrm{CN}$ for the Ga-C scattering path from around 6-7 (at $0.005 \mathrm{~mol} \mathrm{Ga} / \mathrm{mol} \mathrm{R}-\mathrm{COOH}$ ) to $7.2-10.9$ and indicated that we have a different dominant complex in these samples or mixtures of complexes instead of the supposed domination of oxalate-like Ga(III) carboxylic complexes (Table 3, SRN9-11 and SRFA7-9). High CNs for second-shell C atoms are found in metal complexes with artificial chelating agents (e.g., EDTA, NOTA) and these complexes are very stable (Anderegg, 1977; Anderegg et al., 2005). In EDTA and NOTA, Ga(III) is complexed by five and six 5-membered chelate rings, respectively, and surrounded by 10 to $12 \mathrm{C}$ atoms (Wadas et al., 2010). For EDTA, which is the most commonly used chelating agent, 
concentrations have been reported for natural waters $\left(0.52-1120 \mu \mathrm{g} \mathrm{L}^{-1}\right.$; Oviedo and Rodriguez, 2003) that potentially could complex all Ga(III) in the SRN and SRFA samples with the lowest concentrations $\left(1.7-7.2 \mu \mathrm{mol} \mathrm{g}^{-1}\right)$. Another possibility is that ligands capable of forming cage-like structures, as in Ga(III)-EDTA/NOTA, exist within the NOM material and we cannot discern whether the ligands forming these complexes with $\mathrm{Ga}(\mathrm{III})$ are of anthropogenic or natural origin.

It should be noted that the decrease in $\mathrm{CN}$ for $\mathrm{Ga}-\mathrm{C}$ with increasing $\mathrm{Ga}(\mathrm{III})$ to $\mathrm{R}$ $\mathrm{COOH}$ molar ratios, at $\mathrm{pH}$ around 5 (Table 3), could theoretically be a dilution effect. If there is an increase of free $\mathrm{Ga}(\mathrm{III})$ ions with increasing molar ratios (increase in total $\mathrm{Ga}(\mathrm{III})$ concentration), the $\mathrm{CN}$ of $\mathrm{Ga}-\mathrm{C}$ would decrease even though the coordination of the organic $\mathrm{Ga}(\mathrm{III})$ complexes remain the same. However, the distribution diagrams show (Fig. 6) that all samples would be supersaturated with respect to formation of $\mathrm{Ga}(\mathrm{OH})_{3(\mathrm{~s})}$ if they had been prepared in the absence of NOM. This suggest an actual change in coordination of the organic $\mathrm{Ga}$ (III) complexes and a probable explanation is that the ligands/functional groups involved in the complexation at the lowest $\mathrm{Ga}(\mathrm{III})$ to $\mathrm{R}-\mathrm{COOH}$ ratios become saturated at increased $\mathrm{Ga}(\mathrm{III})$ concentration. Another interesting thing to note is that, at a molar ratio of $0.012-0.04(\mathrm{Me} / \mathrm{R}-\mathrm{COOH})$, the structures of the organic $\mathrm{Ga}(\mathrm{III})$ complexes formed are similar to structures obtained for $\mathrm{Fe}(\mathrm{III})$ and $\mathrm{Cu}(\mathrm{II})$ in association with SRN (Karlsson et al., 2006; Karlsson and Persson, 2012). This indicates that the structures obtained for the Ga(III)-SRN complexes at lower molar ratios (0.00030.005), having 6-11 $\mathrm{C}$ atoms in the second shell, also could exist for $\mathrm{Fe}$ and $\mathrm{Cu}$. However, studies of $\mathrm{Fe}$ at these low concentrations are lacking, and would be difficult to 
conduct for reasons discussed above. This clearly demonstrates the benefit of using $\mathrm{Ga}(\mathrm{III})$ as a probe for other metals.

For the samples with highest $\mathrm{Ga}(\mathrm{III})$ concentrations $(0.202 \mathrm{~mol} \mathrm{Ga} / \mathrm{mol} \mathrm{R}$ $\mathrm{COOH}$ ) and $\mathrm{pH}$ values of 4.8-7.0, features characteristic of both $\mathrm{C} / \mathrm{O} / \mathrm{N}$ and $\mathrm{Ga}$ backscattering appeared in the EXAFS spectra (Fig. 5c and d and Fig. 8; Fig. S4h, q and $\mathbf{r}$ and, Fig. S8, Supplementary data). Contributions from organic complexes were weaker than at lower $\mathrm{Ga}(\mathrm{III})$ concentrations, which are reflected by lower $\mathrm{CN}$ for the $\mathrm{Ga}-\mathrm{C}$ scattering path (1.1-2.2) and that fewer scattering paths from the organic structures could be fitted to these spectra (Table 3). This is in line with the IR results indicating that only ca. $10-20 \%$ of the carboxylic sites are available for metal complexation (Fig. 4). Thus, at the highest concentration of $\mathrm{Ga}(\mathrm{III})$, the number of available sites (the same as the amount of added $\mathrm{Ga}(\mathrm{III})$ ) are too few to form chelate complexes with all the added $\mathrm{Ga}(\mathrm{III})$ and the observed $\mathrm{CN}$ for Ga-C can be explained by a mixture of $\mathrm{Ga}(\mathrm{III})-\mathrm{NOM}$ complexes and $\mathrm{Ga}(\mathrm{OH})_{3(\mathrm{~s})}$ and probably some free $\mathrm{Ga}(\mathrm{III})$ at $\mathrm{pH}$ 4.8. The determined distances for $\mathrm{Ga}-\mathrm{C}$ and $\mathrm{Ga}-\mathrm{C}-\mathrm{O}$ at $\mathrm{pH} 4.2-7.0$ are in fair agreement with the $\mathrm{Ga}\left(\mathrm{C}_{2} \mathrm{O}_{4}\right)_{3}{ }^{3-}$ reference (Table 3 and Table S4, Supplementary data). The contribution from Ga backscattering in the samples with highest $\mathrm{Ga}(\mathrm{III})$ concentrations $(0.202 \mathrm{~mol} \mathrm{Ga} / \mathrm{mol} \mathrm{R}$ $\mathrm{COOH}$ ) and $\mathrm{pH}$ values of 4.8-7.0 were fitted with two Ga-Ga scattering paths and the determined distances are in fair agreement with the amorphous $\mathrm{Ga}(\mathrm{OH})_{3(\mathrm{~s})}$ reference (Table 3) and with data reported by Pokrovski et al. (2002) for $\alpha-\mathrm{GaOOH}$ (Table S4, Supplementary data). Addition of a third Ga-Ga scattering path, as in $\mathrm{Ga}(\mathrm{OH})_{3(\mathrm{~s})}$ and $\alpha$ $\mathrm{GaOOH}$, did not significantly improve the fit and an explanation for this could be the complexity of these samples with different Ga species possibly causing interferences 
between scattering paths at similar distances. For all these samples except one (SRN3 at pH 4.8) a significant improvement was obtained by including the two Ga-Ga scattering paths in the fit (see Supplementary data, Table S3). For the samples at $\mathrm{pH} 6.2-7.0$, the CNs for Ga-Ga show approximately the same relationship between the short and the long scattering paths (Table 3) indicating a similar structure of the $\mathrm{Ga}(\mathrm{OH})_{3(\mathrm{~s})}$ phase. However, at $\mathrm{pH} 4.8$ there is lower relative contribution from the short Ga path suggesting a difference in the structure and/or the particle size (Table 3, SRN3 and SRFA2). At pH 3.0-3.1 (0.202 mol Ga/mol R-COOH), the contributions from higher coordination shells were weak and these spectra were similar to the spectrum for $\mathrm{Ga}\left(\mathrm{NO}_{3}\right)_{3(\mathrm{aq})}$, i.e., free Ga(III) (Fig. $8 \mathbf{f}$ and $\mathbf{g}$ and Fig. S8d, Supplementary data). However, since the wavelet plots (Fig. 5b and Fig. S4p, Supplementary data) and the IR results indicated occurrence of organic $\mathrm{Ga}(\mathrm{III})$ complexes, an attempt was made to fit $\mathrm{Ga}-\mathrm{C}$ and $\mathrm{Ga}-\mathrm{C}-\mathrm{O}$ in the second and third shells to these spectra (SRN1 and SRFA1). However, the contribution from these paths were statistically insignificant and resulted in unreasonable fit parameters; therefore only $\mathrm{Ga}-\mathrm{O}$ in the first shell was used in the fit to these samples giving a distance of $1.96 \AA$ (Table 3).

\section{Fig. 8.}

\section{Conclusions and implications for other metals}

The results discussed herein demonstrate similarities between the Ga(III)-NOM system investigated and other metals complexed by NOM, e.g., Fe(III) (Karlsson and Persson, 2012). As for Fe(III), we detected two predominant Ga(III) species: mononuclear Ga(III)- 
NOM complexes and a $\mathrm{Ga}(\mathrm{OH})_{3(\mathrm{~s})}$ phase and a complete domination of organically complexed $\mathrm{Ga}(\mathrm{III})$ at molar ratios of $0.04 \mathrm{Ga} / \mathrm{R}-\mathrm{COOH}\left(16,649 \mu \mathrm{g} \mathrm{Ga}^{-1}\right)$ and below. In addition, our combined EXAFS and IR results showed that NOM interacts with Ga(III) primarily through carboxylic groups, in a large concentration range, forming mononuclear chelate structures stable enough to suppress the hydrolysis and polymerization of the metal. This highlights the importance of these interactions for the solubility and speciation of $\mathrm{Ga}$ and other hydrolyzing metals (e.g., $\mathrm{Fe}, \mathrm{Al}$ ). Knowledge about the distribution between solid and dissolved phases is necessary for understanding the mobility and bioavailability of metals in environmental systems. We detected no significant differences between the two organic materials regarding the structure of the Ga(III)-NOM complexes, but the IR results indicated that the NOM material (SRN) had more active carboxylic sites for metal binding than the fulvic acid (SRFA), ca. 20\% for SRN compared to ca. $10 \%$ for SRFA. This shows that the size and molecular structure of the organic material is probably very important for the complexation of metals. At the

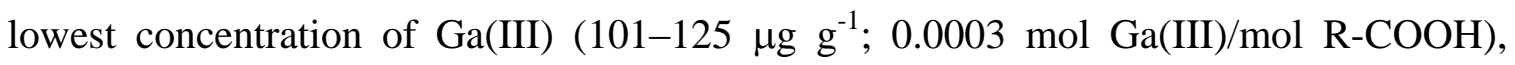
substantially lower than what has been analyzed for Fe(III)-NOM systems, the EXAFS results revealed a change in coordination of the $\mathrm{Ga}(\mathrm{III})-\mathrm{NOM}$ complexes with significantly higher contribution from second-shell C atoms (9-11). This could indicate formation of cage-like structures as in Ga(III)-EDTA, but in order to describe these complexes in more detail additional studies at these low concentrations are needed. The spectroscopic results presented herein for $\mathrm{Ga}(\mathrm{III})-\mathrm{NOM}$ interactions can be used to better understand the behavior of $\mathrm{Ga}$ in soils and surface waters via improvements of thermodynamic speciation models. Furthermore, the similar coordination chemistries of 
$\mathrm{Ga}(\mathrm{III})$ and other metals in NOM, and the fact that Ga can be utilized to extend the experimental range and avoid analytical problems, clearly demonstrates that $\mathrm{Ga}(\mathrm{III})$ indeed can be used as a probe in order to improve our knowledge about Me(III)-NOM interactions in general. In particular, due to the difficulties of analyzing Al using synchrotron-based techniques and similar chemical behavior of $\mathrm{Al}(\mathrm{III})$ and $\mathrm{Ga}(\mathrm{III})$, using $\mathrm{Ga}(\mathrm{III})$ as a probe could be very useful in order to determine the coordination chemistry of $\mathrm{Al}(\mathrm{III})$ in environmental systems.

\section{Acknowledgements}

Portions of this research were carried out at the Stanford Synchrotron Radiation Lightsource, a Directorate of SLAC National Accelerator Laboratory and an Office of Science User Facility operated for the U.S. Department of Energy Office of Science by Stanford University. The SSRL Structural Molecular Biology Program is supported by the DOE Office of Biological and Environmental Research, and by the National Institutes of Health, National Institute of General Medical Sciences (including P41GM103393). The contents of this publication are solely the responsibility of the authors and do not necessarily represent the official views of NIGMS, NCRR, or NIH. Matthew Latimer and the rest of the staff at beamline 4-1 are gratefully acknowledged for their help and advice. We also thank Anneli Sundman from the Department of Chemistry, Umeå University, for help with the EXAFS data collection. The infrared spectroscopy measurements were conducted at the Vibrational Spectroscopy Platform at Umeå University. We also thank three anonymous reviewers and the associate editor, Gleb Pokrovski, for constructive 
suggestions which substantially improved this manuscript. The Knut and Alice Wallenberg foundation is acknowledged for financial support.

\section{Appendix A. Supplementary data}

Supplementary data associated with this article can be found, in the online version, at

\section{References}

Anderegg G. (1977) Critical Survey of Stability Constants of EDTA Complexes. IUPAC Chemical Data Series 14, Pergamon Press, New York.

Anderegg, G., Arnaud-Neu F., Delgado R., Felcman J. and Popov K. (2005) Critical evaluation of stability constants of metal complexes of complexones for biomedical and environmental applications. Pure Appl. Chem. 77, 1445-1495.

Averett R. C., Leenheer J. A., McKnight D. M. and Thorn K. A. (1994) Humic Substances in the Suwannee River, Georgia: Interactions, Properties, and Proposed Structures. USGS Water-Supply Paper, 2373.

Baes C. F. Jr. and Mesmer R. E. (1976) The Hydrolysis of Cations. Wiley, New York.

Bénézeth P., Diakonov I. I., Pokrovski G. S., Dandurand J.-L., Schott J. and Khodakovsky I. L. (1997) Gallium speciation in aqueous solution. Experimental study and modelling: Part 2. Solubility of $\alpha-\mathrm{GaOOH}$ in acidic solutions from 150 to 
$250^{\circ} \mathrm{C}$ and hydrolysis constants of gallium (III) to $300^{\circ} \mathrm{C}$. Geochim. Cosmochim. Acta, 61, 1345-1357.

Boyanov M. I., Kelly S. D., Kemner K. M., Bunker B. A., Fein J. B. and Fowle D. A. (2003) Adsorption of cadmium to Bacillus subtilis bacterial cell walls: A pHdependent X-ray absorption fine structure spectroscopy study. Geochim. Cosmochim. Acta, 67, 3299-3311.

Clausén M., Öhman L.-O., Axe K. and Persson P. (2003) Spectroscopic studies of aluminum and gallium complexes with oxalate and malonate in aqueous solution. $J$. Mol. Struct. 648, 225-235.

Clausén M., Öhman L.-O., Kubicki J. D. and Persson P. (2002) Characterisation of gallium(III)-acetate complexes in aqueous solution: A potentiometric, EXAFS, IR and molecular orbital modelling study. J. Chem. Soc., Dalton Trans. 12, 2559-2564.

Clausén M., Öhman L.-O. and Persson P. (2005) Spectroscopic studies of aqueous gallium(III) and aluminum(III) citrate complexes. J. Inorg. Biochem. 99, 716-726.

Collery P., Keppler B., Madoulet C. and Desoize B. (2002) Gallium in cancer treatment. Crit. Rev. Oncol. Hematol. 42, 283-296.

Duckworth O. W., Bargar J. R. and Sposito G. (2009) Quantitative structure-activity relationships for aqueous metal-siderophore complexes. Environ. Sci. Technol. 43, 343-349.

Elkins K. M. and Nelson D. J. (2002) Spectroscopic approaches to the study of the interaction of aluminum with humic substances. Coord. Chem. Rev. 228, 205-225.

Essington M. E. (2004) Soil and Water Chemistry; An Integrative Approach. CRC Press, Boca Raton, FL. 
Funke H., Scheinost A. C. and Chukalina M. (2005) Wavelet analysis of extended X-ray absorption fine structure data. Phys. Rev. B 71, 094110, 1-7.

Ilina S. M., Poitrasson F., Lapitskiy S. A., Alekhin Y. V., Viers J. and Pokrovsky O. S. (2013) Extreme iron isotope fractionation between colloids and particles of boreal and temperate organic-rich waters. Geochim. Cosmochim. Acta 101, 96-111.

Karlsson T. and Persson P. (2010) Coordination chemistry and hydrolysis of Fe(III) in a peat humic acid studied by X-ray absorption spectroscopy. Geochim. Cosmochim. Acta 74, 30-40.

Karlsson T. and Persson P. (2012) Complexes with aquatic organic matter suppress hydrolysis and precipitation of Fe(III). Chem. Geol. 322-323, 19-27.

Karlsson T., Persson P. and Skyllberg U. (2006) Complexation of copper(II) in organic soils and in dissolved natural organic matter: EXAFS evidence for chelate ring structures. Environ. Sci. Technol. 40, 2623-2628.

Li S. J., Zheng C. and Lobring K. C. (2003) Refinement of the crystal structure of gallium oxide hydroxide, $\mathrm{GaO}(\mathrm{OH})$. Z. Kristallogr. NCS, 218, 11-12.

Lin H. C. and Hwang P. P. (1998) Acute and chronic effects of gallium chloride $\left(\mathrm{GaCl}_{3}\right)$ on tilapia (Oreochromis mossambicus) larvae. Bull. Environ. Contam. Toxicol. 60, 931-935.

Lindqvist-Reis P., Muñoz-Páez A., Díaz-Moreno S., Pattanaik S., Persson I. and Sandström M. (1998) The structure of the hydrated gallium(III), indium(III), and chromium(III) ions in aqueous solution. A large angle X-ray scattering and EXAFS study. Inorg. Chem. 37, 6675-6683. 
Manceau A. and Matynia A. (2010) The nature of $\mathrm{Cu}$ bonding to natural organic matter. Geochim. Cosmochim. Acta 74, 2556-2580.

Martell A. E. and Smith R. M. (1982) Critical Stability Constants. Vol. 5: First Supplement. Plenum Press, New York.

Mikkelsen K. and Nielsen S. O. (1960) Acidity measurements with the glass electrode in $\mathrm{H}_{2} \mathrm{O}-\mathrm{D}_{2} \mathrm{O}$ mixtures. J. Phys. Chem. 64, 632-637.

Mikutta C. (2011) X-ray absorption spectroscopy study on the effect of hydroxybenzoic acids on the formation and structure of ferrihydrite. Geochim. Cosmochim. Acta 75, $5122-5139$.

Norén K. and Persson P. (2010) Co-adsorption of Ga(III) and EDTA at the water- $\alpha-$ $\mathrm{FeOOH}$ interface: Spectroscopic evidence of the formation of ternary surface complexes. J. Phys. Chem. C 114, 16547-16555.

Ogner G. and Schnitzer M. (1971) Chemistry of fulvic acid, a soil humic fraction, and its relation to lignin. Can. J. Chem. 49, 1053-1063.

Oviedo C. and Rodriguez J. (2003) EDTA: the chelating agent under environmental scrutiny. Quim. Nova 26, 901-905.

Patterson H. H., Cronan C. S., Lakshman S., Plankey B. J. and Taylor T. A. (1992) Comparison of soil fulvic acids using synchronous scan fluorescence spectroscopy, FTIR, titration and metal complexation kinetics. Sci. Total Environ. 113, 179-196.

Perrin D. D. (1979) Stability Constants of Metal-Ion Complexes - Part B - Organic Ligands. IUPAC Chemical Data Series 22, Pergamon Press, Oxford. 
Persson P. and Axe K. (2005) Adsorption of oxalate and malonate at the water-goethite interface: Molecular surface speciation from IR spectroscopy. Geochim. Cosmochim. Acta 69, 541-552.

Persson P., Zivkovic K. and Sjöberg S. (2006) Quantitative adsorption and local structures of gallium(III) at the water- $\alpha-\mathrm{FeOOH}$ interface. Langmuir 22, 2096-2104.

Pokrovski G. S., Schott J., Hazemann J.-L., Farges F. and Pokrovsky O. S. (2002) An Xray absorption fine structure and nuclear magnetic resonance spectroscopy study of gallium-silica complexes in aqueous solution. Geochim. Cosmochim. Acta 66, 4203-4222.

Rouhi A. M. (2000) LIGNIN AND LIGNAN BIOSYNTHESIS; Discovery of proteins that guide phenolic radical couplings debunks decades-old notions in this field. Chem. Eng. News 78, 29-32.

Serkiz S. M. and Perdue E. M. (1990) Isolation of dissolved organic matter from the Suwannee River using reverse osmosis. Water Res. 24, 911-916.

Sharma P., Ofner J. and Kappler A. (2010) Formation of binary and ternary colloids and dissolved complexes of organic matter, Fe and As. Environ. Sci. Technol. 44, 44794485.

Thurman E. M. and Malcolm R. L. (1981) Preparative isolation of aquatic humic substances. Environ. Sci. Technol. 15, 463-466.

Wadas T. J., Wong E. H., Weisman G. R. and Anderson C. J. (2010) Coordinating radiometals of copper, gallium, indium, yttrium, and zirconium for PET and SPECT imaging of disease. Chem. Rev. 110, 2858-2902. 
Webb S. M. (2005) SIXpack: a graphical user interface for XAS analysis using IFEFFIT. Phys. Scr. T115, 1011-1014.

Xu R. K., Hu Y. F., Dynes J. J., Zhao A. Z., Blyth R. I. R., Kozak L. M. and Huang P. M. (2010) Coordination nature of aluminum (oxy)hydroxides formed under the influence of low molecular weight organic acids and a soil humic acid studied by X-ray absorption spectroscopy. Geochim. Cosmochim. Acta 74, 6422-6435.

Yang J.-L. and Chen H.-C. (2003) Effects of gallium on common carp (Cyprinus carpio): acute test, serum biochemistry, and erythrocyte morphology. Chemosphere 53, 877882.

Yu H. S. and Liao W. T. (2011) Gallium: environmental pollution and health effects. In Encyclopedia of Environmental Health (ed. O. N. Jerome). Elsevier, Burlington. pp. 829-833.

Zabinsky S. I., Rehr J. J., Ankudinov A., Albers R. C. and Eller M. J. (1995) Multiplescattering calculations of X-ray-absorption spectra. Phys. Rev. B 52, 2995-3009. 


\section{Figure captions}

Fig. 1. A mononuclear $\mathrm{Ga}\left(\mathrm{C}_{2} \mathrm{O}_{4}\right)_{3}{ }^{3-}$ complex with three five-membered chelate rings and indicated interatomic distances from Clausén et al. (2003). The single scattering paths (Ga-O and Ga-C) used to model the organic structures in the $\mathrm{Ga}(\mathrm{III})-\mathrm{NOM}$ samples are indicated with dashed lines and the multiple scattering paths ( $\mathrm{Ga}-\mathrm{O}-\mathrm{C}$ and $\mathrm{Ga}-\mathrm{C}-\mathrm{O})$ with dotted lines.

Fig. 2. Infrared spectra illustrating the differences between the Ga(III)-SRN system and the reference SRN system in the $\mathrm{pH}$ range 3-8 (the two groups of spectra are offset vertically for clarity). Spectra of the Ga(III)-SRN samples, IR_SRN7-12, (top) and spectra of the reference samples, IR_SRN1-6, (bottom) at pH 7.9 (top)/8.1 (bottom) (orange lines), 6.7/6.7 (black), 5.8/5.9 (purple), 4.7/5.1 (green), 3.8/4.1 (red), and 3.2/3.1 (blue). The arrows shows if the absorbance of the IR peaks increase $(\uparrow)$ or decrease $(\downarrow)$ when $\mathrm{pH}$ increases. The two vertical lines indicate the start- (left line) and end-position (right line) of the asymmetric carboxylate peak in the reference SRN system when going from low to high $\mathrm{pH}$.

Fig. 3. Difference spectra showing the contribution from the Ga(III)-SRN complex in the carboxylate region, isolated by subtracting the spectra of protonated and non-protonated SRN from the spectra of Ga(III)-SRN at pH 3.2 (IR_SRN7), pH 3.8 (IR_SRN8), pH 4.7 (IR_SRN9), pH 5.8 (IR_SRN10), pH 6.7 (IR_SRN11), and pH 7.9 (IR_SRN12) (the spectra are offset for clarity). Vertical dashed lines mark the symmetric and asymmetric carboxylate stretching frequencies at 1432 and $1615 \mathrm{~cm}^{-1}$, respectively. 
Fig. 4. Fraction of coordinated carboxyl groups in SRN and SRFA as a function of pH and at different $\mathrm{Ga}(\mathrm{III}): \mathrm{R}-\mathrm{COOH}$ ratios: 0.202 (IR_SRN7-12, IR_SRN22-26, and IR_SRFA1-3) and 0.17-0.07 (IR_SRN13-15). Data for the IR_SRN22-26, IR_SRN1315, and IR_SRFA1-3 samples are found in Table S2 (Supplementary data).

Fig. 5. High resolution WT modulus displaying the second and third coordination shells (MORLET parameters, $\eta=10, \sigma=1$ ) of a) $\mathrm{Ga}(\mathrm{OH})_{3(\mathrm{~s})}$, b) SRN1 (pH 3.0; Ga:R-COOH ratio 0.202), c) SRN3 (pH 4.8; Ga:R-COOH ratio 0.202), d) SRN5 (pH 6.8; Ga:R-COOH ratio 0.202), e) $\mathrm{Ga}\left(\mathrm{C}_{2} \mathrm{O}_{4}\right)_{3}{ }^{3-}$, f) SRN7 (pH 5.2; Ga:R-COOH ratio 0.04), g) SRN9 (pH 4.9; Ga:R-COOH ratio 0.005), and h) SRN11 (pH 5.1; Ga:R-COOH ratio 0.0003), plotted as a function of $k\left(\AA^{-1}\right)$ on the $\mathrm{x}$-axis, in the range $2-15$, and $R(\AA)$ on the y-axis in the range 2.0-4.0 (not corrected for phase shift). The white/brown areas indicate strong contribution from back-scattering atoms whereas the blue/green areas indicate no or weak contribution.

Fig. 6. Distribution of $\mathrm{Ga}(\mathrm{III})$ species as a function of $\mathrm{pH}$ at $\mathbf{A})[\mathrm{Ga}(\mathrm{III})]$ tot $=44.8 \mathrm{mM}$, and B) $[\mathrm{Ga}(\mathrm{III})]$ tot $=0.27 \mathrm{mM}$. Calculations were performed with stability constants from Clausén et al. (2002), Bénézeth et al. (1997), and Baes and Mesmer (1976). The solid phase considered is amorphous $\mathrm{Ga}(\mathrm{OH})_{3(\mathrm{~s})}$. 
Fig. 7. $k^{3}$-weighted EXAFS spectra (solid line) with fit results (dotted line) A) and the corresponding Fourier Transforms (solid line), not corrected for phase shift, together with fit results (dotted line) B) of the Suwannee river NOM and fulvic acid at $\mathrm{pH}$ and $\mathrm{Ga}$ (III) to $\mathrm{R}-\mathrm{COOH}$ ratio of a) 5 and 0.005 (SRFA7), b) 3 and 0.04 (SRN6), c) 5 and 0.04 (SRN7), d) 7 and 0.04 (SRN8), e) 5 and 0.005 (SRN9), f) 5 and 0.0012 (SRN10), g) 5 and 0.0003 (SRN11), and h) $\mathrm{Ga}\left(\mathrm{C}_{2} \mathrm{O}_{4}\right)_{3}{ }^{3-}$ (Clausén et al., 2003). The vertical dashed lines indicate approximate positions for the main atomic neighbors and multiple scattering (MS) contributions in $\mathrm{Ga}\left(\mathrm{C}_{2} \mathrm{O}_{4}\right)_{3}{ }^{3-}$.

Fig. 8. $k^{3}$-weighted EXAFS spectra (solid line) with fit results (dotted line) A) and the corresponding Fourier Transforms (solid line), not corrected for phase shift, together with fit results (dotted line) B) of the Suwannee river NOM samples at a Ga(III) to R-COOH ratio of 0.202 and a $\mathrm{pH}$ of a) $\mathrm{Ga}(\mathrm{OH})_{3(\mathrm{~s})}$, b) 7 (SRN5), c) 6 (SRN4), d) 5 (SRN3), e) 4 (SRN2), f) 3 (SRN1), and g) $\mathrm{Ga}\left(\mathrm{NO}_{3}\right)_{3(\mathrm{aq})}$. The vertical dashed lines indicate approximate positions for the main atomic neighbors in $\mathrm{Ga}(\mathrm{OH})_{3(\mathrm{~s})}$. 
Table 1

Data for the Suwannee River NOM (SRN) samples prepared for infrared analysis.

\begin{tabular}{|c|c|c|c|c|c|c|c|}
\hline Sample & $\begin{array}{l}\text { NOM } \\
(\mathrm{mq})^{\mathrm{a}}\end{array}$ & $\begin{array}{c}\begin{array}{c}\text { Volume } \\
(\mathrm{mL})^{\mathrm{b}}\end{array} \\
\end{array}$ & $\mathrm{pH}$ & $\begin{array}{l}{[\mathrm{Ga}(\mathrm{III})]} \\
\left(\mu \mathrm{q} \mathrm{q}^{-1}\right)^{\mathrm{c}}\end{array}$ & $\begin{array}{c}\text { Ga(III) } \\
(\mu \mathrm{mol})^{d}\end{array}$ & $\begin{array}{l}{[\mathrm{Ga}(\mathrm{III})]} \\
(\mathrm{mM})^{\mathrm{e}}\end{array}$ & $\begin{array}{c}\mathrm{Ga}(\mathrm{III}) \\
/ \mathrm{R}-\mathrm{COOH}^{\mathrm{f}}\end{array}$ \\
\hline IR_SRN1 & 28 & 0.30 & 3.1 & 0 & 0 & 0 & 0 \\
\hline IR_SRN2 & 28 & 0.30 & 4.1 & 0 & 0 & 0 & 0 \\
\hline IR_SRN3 & 28 & 0.30 & 5.1 & 0 & 0 & 0 & 0 \\
\hline IR_SRN4 & 28 & 0.30 & 5.9 & 0 & 0 & 0 & 0 \\
\hline IR_SRN5 & 28 & 0.30 & 6.7 & 0 & 0 & 0 & 0 \\
\hline IR_SRN6 & 28 & 0.30 & 8.1 & 0 & 0 & 0 & 0 \\
\hline IR_SRN7 & 28 & 0.50 & 3.2 & 67,673 & 26.8 & 53.6 & 0.202 \\
\hline IR_SRN8 & 28 & 0.50 & 3.8 & 67,673 & 26.8 & 53.6 & 0.202 \\
\hline IR_SRN9 & 28 & 0.50 & 4.7 & 67,673 & 26.8 & 53.6 & 0.202 \\
\hline IR_SRN10 & 28 & 0.50 & 5.8 & 67,673 & 26.8 & 53.6 & 0.202 \\
\hline IR_SRN11 & 28 & 0.50 & 6.7 & 67,673 & 26.8 & 53.6 & 0.202 \\
\hline IR_SRN12 & 28 & 0.50 & 7.9 & 67,673 & 26.8 & 53.6 & 0.202 \\
\hline
\end{tabular}

${ }^{\mathrm{a}}$ The amount of natural organic matter (NOM) in dry weight.

${ }^{\mathrm{b}}$ The total solution volume.

${ }^{\mathrm{c}}$ The weight of Ga per gram of NOM.

${ }^{\mathrm{d}}$ The amount of $\mathrm{Ga}$ in micromoles.

e The concentration of $\mathrm{Ga}$ in millimolar.

${ }^{\dagger}$ Mol Ga per mol of carboxylic acid. 
Table 2

Composition of the Suwannee River NOM (SRN) and fulvic acid (SRFA) samples prepared for EXAFS analysis.

\begin{tabular}{|c|c|c|c|c|c|c|c|}
\hline Sample & $\operatorname{NOM}(\mathrm{mg})^{\mathrm{a}}$ & $\begin{array}{c}\text { Volume } \\
(\mathrm{mL})^{\mathrm{b}}\end{array}$ & $\mathrm{pH}$ & $\begin{array}{l}{[\mathrm{Ga}(\mathrm{III})]} \\
\left(\mu \mathrm{q} \mathrm{q} \mathrm{q}^{-1}\right)^{\mathrm{c}}\end{array}$ & $\begin{array}{c}\mathrm{Ga}(\mathrm{III}) \\
(\text { umol) }\end{array}$ & $\begin{array}{c}{[\mathrm{Ga}(\mathrm{III})]} \\
(\mathrm{mM})^{\mathrm{e}}\end{array}$ & $\begin{array}{c}\mathrm{Ga}(\mathrm{III}) \\
/ \mathrm{R}-\mathrm{COOH}^{\mathrm{f}}\end{array}$ \\
\hline SRN1 & 18 & 0.50 & 3.0 & 67,673 & 17.9 & 35.8 & 0.202 \\
\hline SRN2 & 18 & 0.50 & 4.2 & 67,673 & 17.9 & 35.8 & 0.202 \\
\hline SRN3 & 18 & 0.50 & 4.8 & 67,673 & 17.9 & 35.8 & 0.202 \\
\hline SRN4 & 18 & 0.50 & 6.2 & 67,673 & 17.9 & 35.8 & 0.202 \\
\hline SRN5 & 18 & 0.50 & 6.8 & 67,673 & 17.9 & 35.8 & 0.202 \\
\hline SRN6 & 23 & 0.25 & 3.3 & 13,401 & 4.48 & 17.9 & 0.04 \\
\hline SRN7 & 23 & 0.25 & 5.2 & 13,401 & 4.48 & 17.9 & 0.04 \\
\hline SRN8 & 23 & 0.25 & 6.9 & 13,401 & 4.48 & 17.9 & 0.04 \\
\hline SRN9 & 37 & 0.25 & 4.9 & 1675 & 0.90 & 3.58 & 0.005 \\
\hline SRN10 & 37 & 0.25 & 5.0 & 402 & 0.21 & 0.85 & 0.0012 \\
\hline SRN11 & 46 & 0.25 & 5.1 & 101 & 0.07 & 0.27 & 0.0003 \\
\hline SRFA1 & 18 & 0.50 & 3.1 & 84,076 & 22.4 & 44.8 & 0.202 \\
\hline SRFA2 & 18 & 0.50 & 4.8 & 84,076 & 22.4 & 44.8 & 0.202 \\
\hline SRFA3 & 18 & 0.50 & 7.0 & 84,076 & 22.4 & 44.8 & 0.202 \\
\hline SRFA4 & 23 & 0.25 & 2.9 & 16,649 & 5.37 & 21.5 & 0.04 \\
\hline SRFA5 & 23 & 0.25 & 5.0 & 16,649 & 5.37 & 21.5 & 0.04 \\
\hline SRFA6 & 23 & 0.25 & 6.5 & 16,649 & 5.37 & 21.5 & 0.04 \\
\hline SRFA7 & 27 & 0.25 & 4.7 & 2081 & 0.81 & 3.26 & 0.005 \\
\hline SRFA8 & 32 & 0.25 & 5.2 & 499 & 0.23 & 0.93 & 0.0012 \\
\hline SRFA9 & 46 & 0.25 & 4.9 & 125 & 0.08 & 0.32 & 0.0003 \\
\hline
\end{tabular}

${ }^{a}$ The amount of natural organic matter (NOM) in dry weight.

${ }^{b}$ The total solution volume.

${ }^{c}$ The weight of Ga per gram of NOM.

${ }^{\mathrm{d}}$ The amount of $\mathrm{Ga}$ in micromoles.

e The concentration of $\mathrm{Ga}$ in millimolar.

${ }^{\dagger}$ Mol Ga per mol of carboxylic acid. 
Table 3

Fits to Fourier-transformed EXAFS data for $\mathrm{Ga}(\mathrm{OH})_{3(\mathrm{~s})}$ and the Suwannee River NOM (SRN) and fulvic acid (SRFA) samples.

\begin{tabular}{|c|c|c|c|c|c|c|c|c|c|c|c|c|c|c|c|c|c|}
\hline \multirow[b]{2}{*}{ Sample } & \multirow[b]{2}{*}{ pH } & \multirow{2}{*}{$\begin{array}{c}\text { Molar } \\
\text { ratio }\end{array}$} & \multicolumn{3}{|c|}{ Ga-O/N (SS) } & \multicolumn{2}{|c|}{ Ga-C (SS) ${ }^{c, f}$} & \multicolumn{2}{|c|}{ Ga-O-C (MS) ${ }^{\mathrm{d}, \mathrm{f}}$} & \multicolumn{2}{|c|}{ Ga-C-O (MS) ${ }^{\mathrm{e}, \mathrm{f}}$} & \multicolumn{2}{|c|}{ Ga-Ga (SS) ${ }^{g}$} & \multicolumn{2}{|c|}{ Ga-Ga (SS) ${ }^{g}$} & \multirow{2}{*}{$\begin{array}{l}\Delta \mathrm{E}_{0} \\
(\mathrm{eV})\end{array}$} & \multirow[t]{2}{*}{ R-factor } \\
\hline & & & $\mathrm{CN}$ & $R(\AA)^{b}$ & $\sigma^{2}\left(\AA^{2}\right)$ & $\mathrm{CN}^{\mathrm{f}}$ & $R(\AA)$ & $\mathrm{CN}^{f}$ & $R(\AA)$ & $\mathrm{CN}^{\dagger}$ & $R(\AA)$ & $\mathrm{CN}$ & $R(\AA)$ & $\mathrm{CN}$ & $R(\AA)$ & & \\
\hline \multirow[t]{2}{*}{$\overline{\mathrm{Ga}(\mathrm{OH})_{3}{ }^{\mathrm{a}}}$} & & & $6.0 \pm 0.8$ & 1.96 & $0.0111 \pm 0.002$ & & & & & & & 2 & $2.99 \pm 0.03$ & 4 & $3.52 \pm 0.04$ & $3.4 \pm 1.5$ & 0.0093 \\
\hline & & & & & & & & & & & & 2 & $3.10 \pm 0.03$ & & & & \\
\hline SRN1 & 3.0 & 0.202 & $5.6 \pm 0.5$ & 1.96 & $0.0071 \pm 0.001$ & & & & & & & & & & & $6.8 \pm 1.1$ & 0.0238 \\
\hline SRN2 & 4.2 & 0.202 & $5.6 \pm 0.4$ & 1.96 & $0.0072 \pm 0.001$ & $1.7 \pm 0.6$ & $2.70 \pm 0.03$ & & & 3.4 & $4.16 \pm 0.06$ & & & & & $6.2 \pm 0.8$ & 0.0117 \\
\hline SRN3* & 4.8 & 0.202 & $5.3 \pm 0.7$ & 1.95 & $0.0073 \pm 0.001$ & $2.2 \pm 1.1$ & $2.70 \pm 0.05$ & & & 4.4 & $4.08 \pm 0.11$ & $0.4 \pm 0.3$ & $3.06 \pm 0.06$ & $3.2 \pm 2.3$ & $3.56 \pm 0.05$ & $6.5 \pm 1.5$ & 0.0140 \\
\hline SRN4 & 6.2 & 0.202 & $5.3 \pm 0.6$ & 1.95 & $0.0089 \pm 0.001$ & $1.7 \pm 0.8$ & $2.72 \pm 0.05$ & & & 3.4 & $4.06 \pm 0.10$ & $1.1 \pm 0.3$ & $3.06 \pm 0.01$ & $3.4 \pm 1.6$ & $3.55 \pm 0.03$ & $7.0 \pm 1.2$ & 0.0082 \\
\hline SRN5 & 6.8 & 0.202 & $5.3 \pm 0.7$ & 1.94 & $0.0112 \pm 0.001$ & $1.6 \pm 0.8$ & $2.76 \pm 0.05$ & & & 3.2 & $4.06 \pm 0.10$ & $1.0 \pm 0.3$ & $3.06 \pm 0.02$ & $3.1 \pm 1.5$ & $3.56 \pm 0.04$ & $7.4 \pm 1.3$ & 0.0091 \\
\hline SRN6 & 3.3 & 0.04 & $5.5 \pm 0.3$ & 1.97 & $0.0068 \pm 0.001$ & $3.0 \pm 0.6$ & $2.78 \pm 0.02$ & 6.0 & $3.05 \pm 0.08$ & 6.0 & $4.12 \pm 0.03$ & & & & & $7.6 \pm 0.7$ & 0.0083 \\
\hline SRN7 & 5.2 & 0.04 & $5.5 \pm 0.3$ & 1.96 & $0.0076 \pm 0.001$ & $3.8 \pm 0.5$ & $2.76 \pm 0.01$ & 7.6 & $3.02 \pm 0.05$ & 7.6 & $4.09 \pm 0.02$ & & & & & $7.3 \pm 0.6$ & 0.0059 \\
\hline SRN8 & 6.9 & 0.04 & $5.5 \pm 0.3$ & 1.95 & $0.0100 \pm 0.001$ & $3.8 \pm 0.3$ & $2.77 \pm 0.01$ & 7.6 & $3.02 \pm 0.04$ & 7.6 & $4.09 \pm 0.02$ & & & & & $7.7 \pm 0.5$ & 0.0046 \\
\hline SRN9 & 4.9 & 0.005 & $5.3 \pm 0.4$ & 1.97 & $0.0060 \pm 0.001$ & $6.9 \pm 1.1$ & $2.76 \pm 0.01$ & 13.8 & $3.06 \pm 0.06$ & 13.8 & $4.09 \pm 0.02$ & & & & & $7.6 \pm 0.9$ & 0.0153 \\
\hline SRN10 & 5.0 & 0.0012 & $5.0 \pm 0.6$ & 1.97 & $0.0061 \pm 0.001$ & $7.2 \pm 1.1$ & $2.74 \pm 0.02$ & 14.4 & $3.04 \pm 0.07$ & 14.4 & $4.08 \pm 0.03$ & & & & & $6.5 \pm 1.2$ & 0.0141 \\
\hline SRN11 & 5.1 & 0.0003 & $5.6 \pm 1.1$ & 1.97 & $0.0046 \pm 0.002$ & $10.9 \pm 2.1$ & $2.76 \pm 0.02$ & 21.8 & $3.07 \pm 0.09$ & 21.8 & $4.11 \pm 0.04$ & & & & & $6.2 \pm 1.7$ & 0.0231 \\
\hline SRFA1 & 3.1 & 0.202 & $5.4 \pm 0.5$ & 1.96 & $0.0062 \pm 0.001$ & & & & & & & & & & & $6.3 \pm 1.3$ & 0.0234 \\
\hline SRFA2 & 4.8 & 0.202 & $5.6 \pm 0.5$ & 1.95 & $0.0079 \pm 0.001$ & $1.4 \pm 0.6$ & $2.68 \pm 0.04$ & & & 2.8 & $4.06 \pm 0.09$ & $0.6 \pm 0.2$ & $3.06 \pm 0.02$ & $3.3 \pm 1.5$ & $3.55 \pm 0.03$ & $5.9 \pm 1.0$ & 0.0074 \\
\hline SRFA3 & 7.0 & 0.202 & $5.1 \pm 0.5$ & 1.93 & $0.0094 \pm 0.001$ & $1.1 \pm 0.6$ & $2.66 \pm 0.05$ & & & 2.2 & $3.98 \pm 0.11$ & $1.4 \pm 0.2$ & $3.04 \pm 0.01$ & $3.1 \pm 1.3$ & $3.50 \pm 0.04$ & $6.3 \pm 1.2$ & 0.0098 \\
\hline SRFA4 & 2.9 & 0.04 & $5.8 \pm 0.3$ & 1.96 & $0.0065 \pm 0.001$ & $2.4 \pm 0.6$ & $2.77 \pm 0.02$ & 4.8 & $3.05 \pm 0.09$ & 4.8 & $4.10 \pm 0.04$ & & & & & $6.0 \pm 0.7$ & 0.0090 \\
\hline SRFA5 & 5.0 & 0.04 & $5.7 \pm 0.3$ & 1.96 & $0.0071 \pm 0.001$ & $3.0 \pm 0.4$ & $2.76 \pm 0.01$ & 6.0 & $3.04 \pm 0.06$ & 6.0 & $4.08 \pm 0.02$ & & & & & $6.1 \pm 0.6$ & 0.0059 \\
\hline SRFA6 & 6.5 & 0.04 & $6.1 \pm 0.4$ & 1.95 & $0.0098 \pm 0.001$ & $3.5 \pm 0.5$ & $2.76 \pm 0.01$ & 7.0 & $3.07 \pm 0.06$ & 7.0 & $4.09 \pm 0.02$ & & & & & $6.5 \pm 0.7$ & 0.0088 \\
\hline SRFA7 & 4.7 & 0.005 & $5.4 \pm 0.6$ & 1.97 & $0.0058 \pm 0.001$ & $6.4 \pm 1.2$ & $2.76 \pm 0.01$ & 12.8 & $3.06 \pm 0.06$ & 12.8 & $4.08 \pm 0.03$ & & & & & $7.6 \pm 1.1$ & 0.0216 \\
\hline SRFA8 & 5.2 & 0.0012 & $5.5 \pm 0.4$ & 1.98 & $0.0056 \pm 0.001$ & $7.6 \pm 0.7$ & $2.76 \pm 0.01$ & 15.2 & $3.06 \pm 0.04$ & 15.2 & $4.10 \pm 0.02$ & & & & & $8.2 \pm 0.8$ & 0.0097 \\
\hline SRFA9 & 4.9 & 0.0003 & $5.7 \pm 1.2$ & 1.98 & $0.0050 \pm 0.002$ & $9.4 \pm 1.9$ & $2.76 \pm 0.02$ & 18.8 & $3.11 \pm 0.09$ & 18.8 & $4.12 \pm 0.04$ & & & & & $5.7 \pm 1.6$ & 0.0265 \\
\hline
\end{tabular}

The following abbreviations are used: single scattering (SS), multiple scattering (MS), coordination number $(\mathrm{CN})$, bond distance (R), Debye-Waller factor $\left(\sigma^{2}\right)$ and edge energy $\left(\Delta \mathrm{E}_{0}\right)$. $\mathrm{S}_{0}{ }^{2}$ was set to 1.21 for the SRN and SRFA samples (see text) and detemined to 0.98 for $\mathrm{Ga}(\mathrm{OH})_{3}$ by fitting the first coordination shell with a fixed $\mathrm{CN}$ of 6.0.

${ }^{a} \mathrm{CNs}$ for the three Ga-Ga scattering paths were fixed according to data reported by Pokrovski et al. (2002) for a-GaOOH and the $\sigma^{2}: s$ were determined to be $0.0078 \pm 0.006$ (at $2.99 \AA$ ), $0.0057 \pm 0.004$ (at $3.10 \AA$ ) and $0.0185 \pm 0.005$ (at $3.52 \AA$ ) .

${ }^{\mathrm{b}}$ The uncertainty for the determined Ga-O distances is \pm 0.01 .

${ }^{c}$ For SRN9 $\sigma^{2}$ was determined to be $0.0092 \pm 0.005$ and this value was used for the samples SRN2-11. Similarly, $\sigma^{2}$ was determined to be $0.0071 \pm 0.005$ for SRFA7 and this value was used for the samples SRFA2-9.

${ }^{d}$ For SRN9 $\sigma 2$ was determined to be $0.0099 \pm 0.008$ and this value was used for the samples SRN6-11. Similarly, $\sigma^{2}$ was determined to be $0.0076 \pm 0.007$ for SRFA7 and this value was used for the samples SRFA4-9.

${ }^{e}$ For SRN9 $\sigma^{2}$ was determined to be $0.0145 \pm 0.003$ and this value was used for the samples SRN2-11. Similarly, $\sigma^{2}$ was determined to be $0.0128 \pm 0.004$ for SRFA7 and this value was used for the samples SRFA2-9.

${ }^{\dagger} \mathrm{CNs}$ of these scattering paths were correlated as follows: $2 \times \mathrm{CN}(\mathrm{Ga}-\mathrm{C}(\mathrm{SS}))=\mathrm{CN}(\mathrm{Ga}-\mathrm{O}-\mathrm{C}(\mathrm{MS}))=\mathrm{CN}(\mathrm{Ga}-\mathrm{C}-\mathrm{O}(\mathrm{MS}))$, in accordance with the Ga( $\left.\mathrm{C}_{2} \mathrm{O}_{4}\right)_{3}{ }^{3-}$ structure.

${ }^{9}$ For the samples SRN3-5 and SRFA2-3 the $\sigma^{2}$ :s for the short and the long Ga-Ga scattering paths were fixed at 0.0078 and 0.0185 . respectively, which are the values determined for Ga(OH) ${ }_{3}$.

*Inclusion of the two Ga-Ga scattering paths in the fit did not result in a significant improvement (see Table S3, Supplementary data). However, since the WT analysis showed a clear contribution from Ga-Ga backscattering in this sample we decided to keep these paths in the reported fit. 


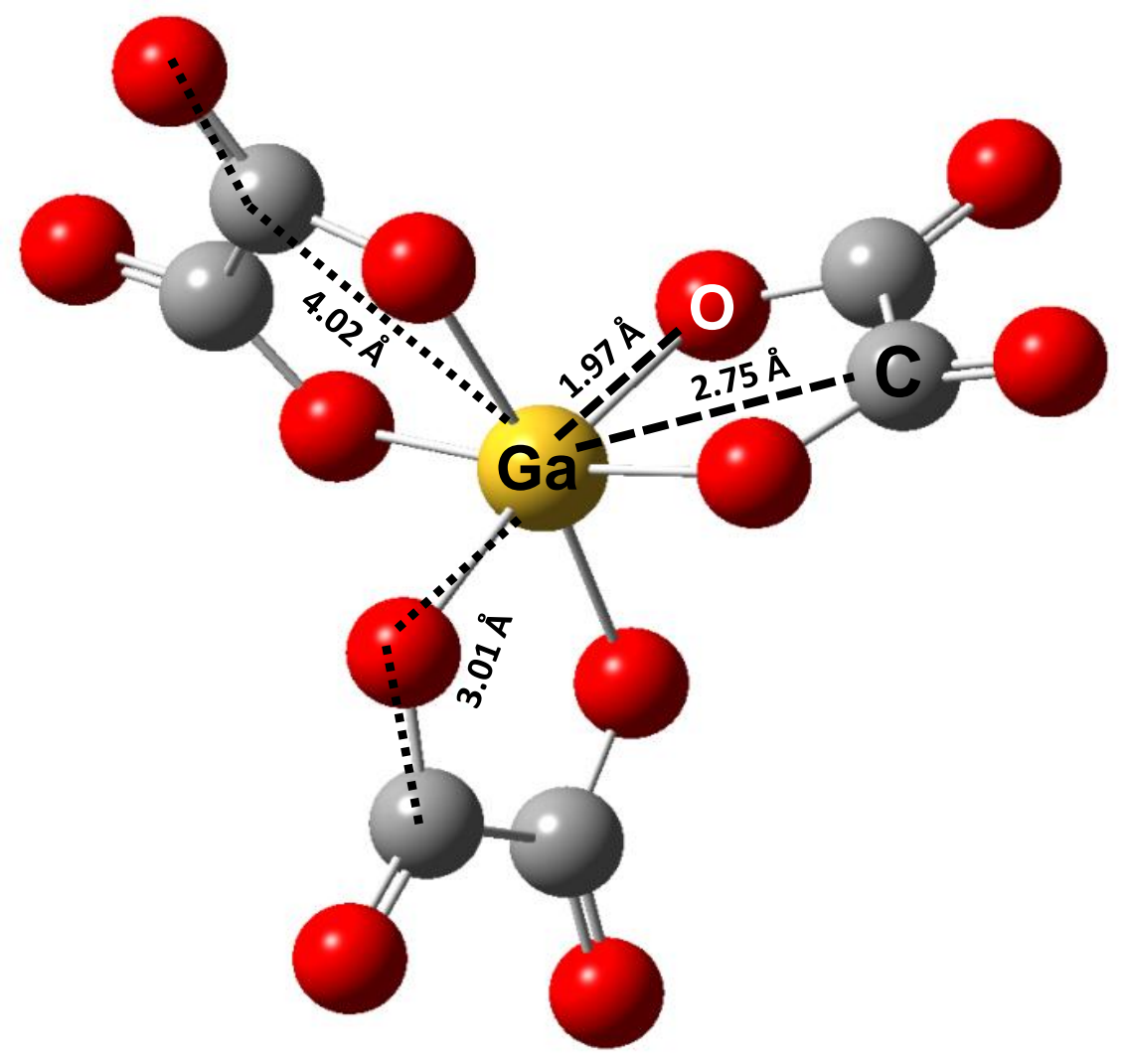




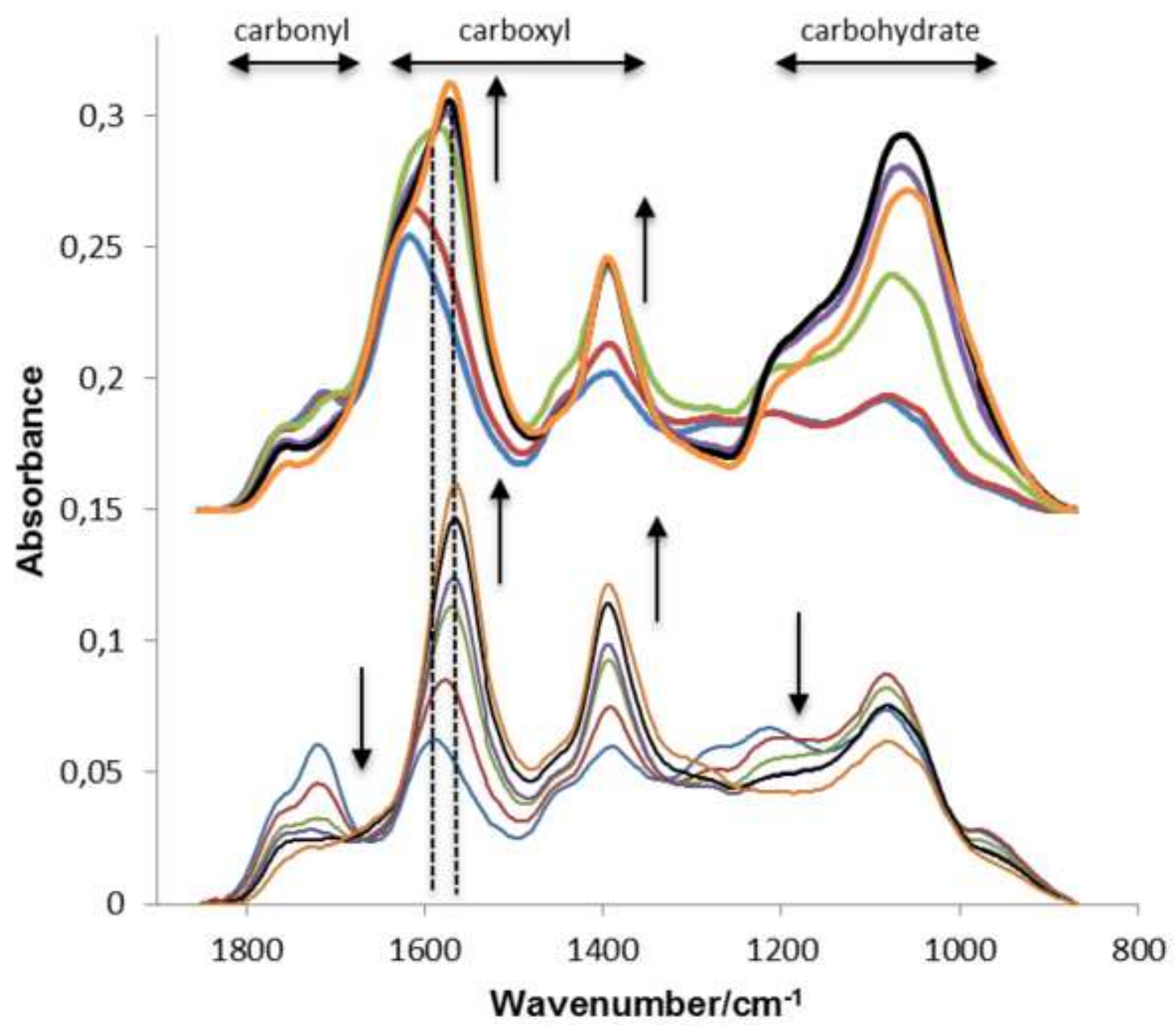


Figure 3

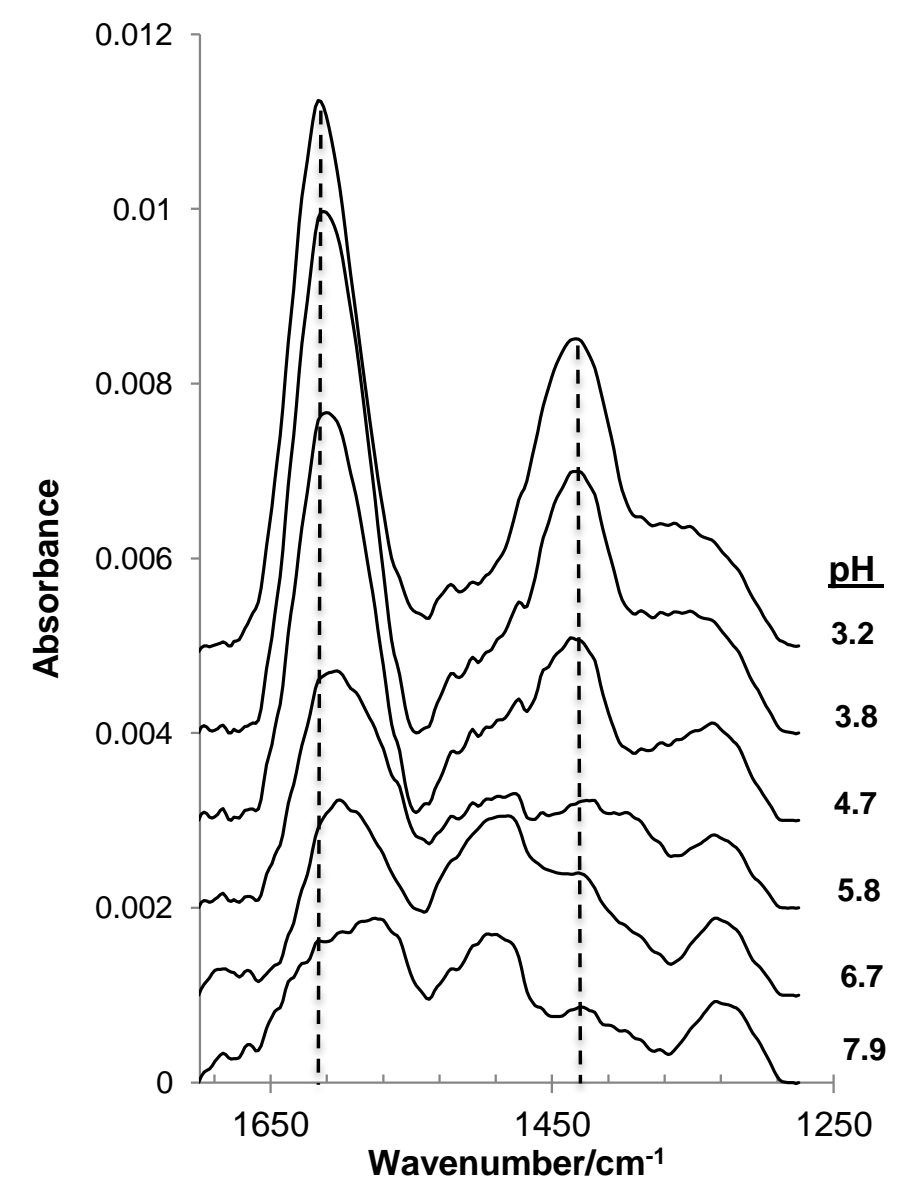



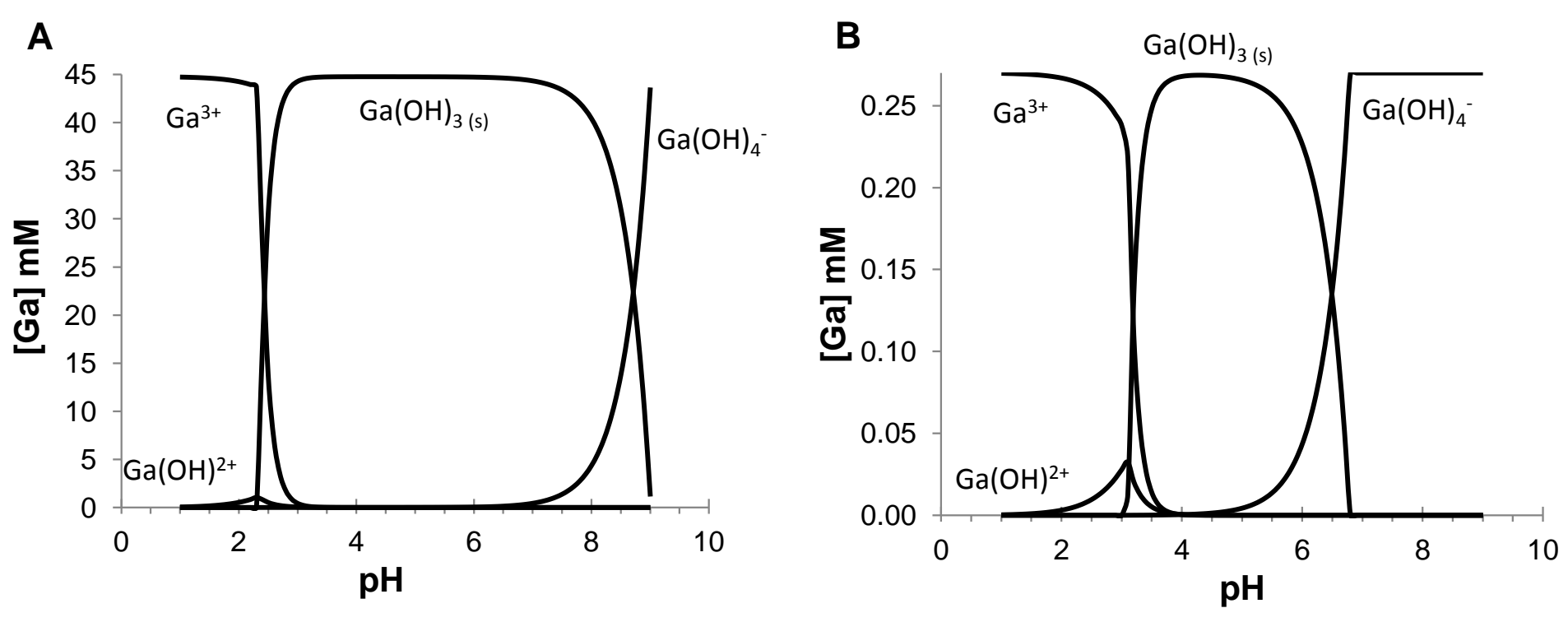

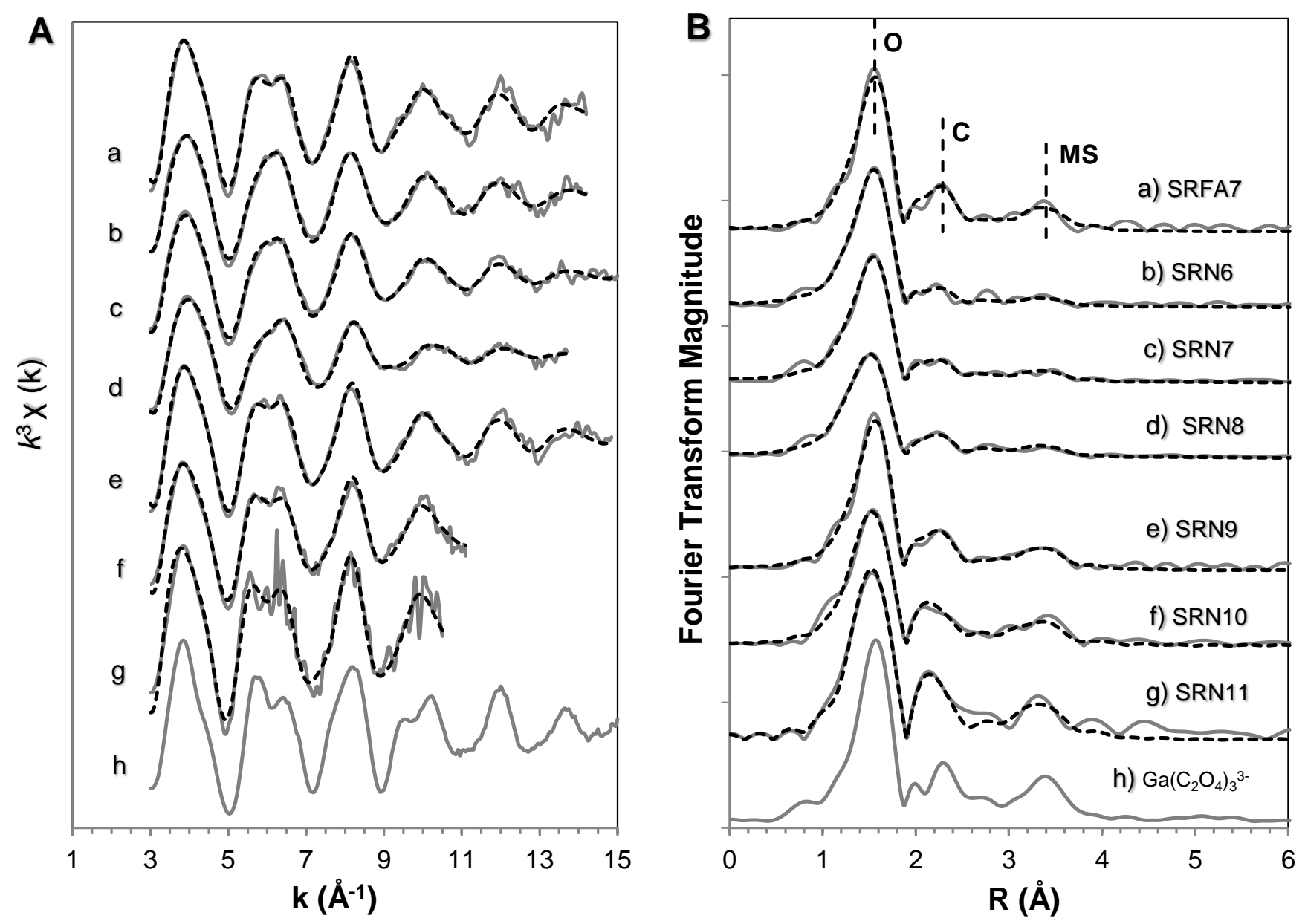

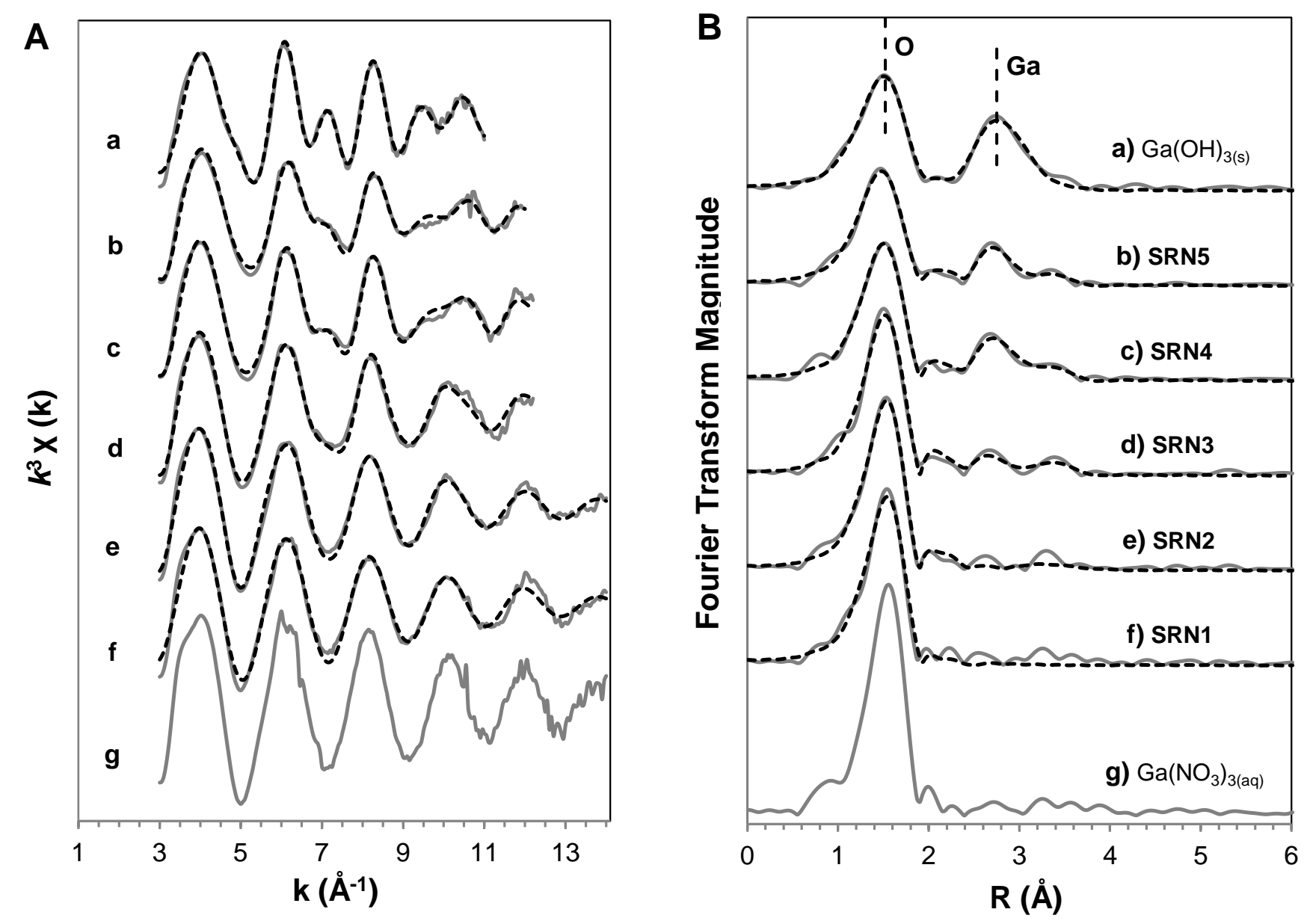